\title{
Simulation of stratospheric water vapor trends: impact on stratospheric ozone chemistry
}

\author{
A. Stenke and V. Grewe \\ Deutsches Zentrum für Luft- und Raumfahrt (DLR), Institut für Physik der Atmosphäre, Oberpfaffenhofen, 82230 Weßling, \\ Germany
}

Received: 16 August 2004 - Published in Atmos. Chem. Phys. Discuss.: 14 October 2004

Revised: 7 February 2005 - Accepted: 16 April 2005 - Published: 31 May 2005

\begin{abstract}
A transient model simulation of the 40-year time period 1960 to 1999 with the coupled climate-chemistry model (CCM) ECHAM4.L39(DLR)/CHEM shows a stratospheric water vapor increase over the last two decades of 0.7 ppmv and, additionally, a short-term increase after major volcanic eruptions. Furthermore, a long-term decrease in global total ozone as well as a short-term ozone decline in the tropics after volcanic eruptions are modeled. In order to understand the resulting effects of the water vapor changes on lower stratospheric ozone chemistry, different perturbation simulations were performed with the CCM ECHAM4.L39(DLR)/CHEM feeding the water vapor perturbations only to the chemistry part. Two different long-term perturbations of lower stratospheric water vapor, $+1 \mathrm{ppmv}$ and $+5 \mathrm{ppmv}$, and a short-term perturbation of +2 ppmv with an e-folding time of two months were applied. An additional stratospheric water vapor amount of 1 ppmv results in a 5-10\% $\mathrm{OH}$ increase in the tropical lower stratosphere between 100 and $30 \mathrm{hPa}$. As a direct consequence of the $\mathrm{OH}$ increase the ozone destruction by the $\mathrm{HO}_{\mathrm{x}}$ cycle becomes $6.4 \%$ more effective. Coupling processes between the $\mathrm{HO}_{\mathrm{x}}$-family and the $\mathrm{NO}_{\mathrm{x}} / \mathrm{ClO}_{\mathrm{x}}-$ family also affect the ozone destruction by other catalytic reaction cycles. The $\mathrm{NO}_{\mathrm{x}}$ cycle becomes $1.6 \%$ less effective, whereas the effectiveness of the $\mathrm{ClO}_{\mathrm{x}}$ cycle is again slightly enhanced. A long-term water vapor increase does not only affect gas-phase chemistry, but also heterogeneous ozone chemistry in polar regions. The model results indicate an enhanced heterogeneous ozone depletion during antarctic spring due to a longer PSC existence period. In contrast, PSC formation in the northern hemisphere polar vortex and therefore heterogeneous ozone depletion during arctic spring are not affected by the water vapor increase, because of the less PSC activity. Finally, this study shows that $10 \%$ of the global total ozone decline in the transient model run can
\end{abstract}

Correspondence to: A. Stenke

(andrea.stenke@dlr.de) be explained by the modeled water vapor increase, but the simulated tropical ozone decrease after volcanic eruptions is caused dynamically rather than chemically.

\section{Introduction}

Water vapor in the upper troposphere (UT) and lower stratosphere (LS) plays a key role in atmospheric chemistry. The oxidation of $\mathrm{H}_{2} \mathrm{O}$ and $\mathrm{CH}_{4}$ by excited oxygen $\mathrm{O}\left({ }^{1} \mathrm{D}\right)$ is the primary source of hydrogen oxides $\left(\mathrm{HO}_{\mathrm{x}}=\mathrm{OH}+\mathrm{HO}_{2}\right)($ Reactions R1-R2, see Appendix), which are involved in important catalytic reaction cycles that control the production and destruction of ozone in the LS. The importance of the catalytic $\mathrm{HO}_{\mathrm{x}}$-cycles for the photochemistry of stratospheric $\mathrm{O}_{3}$ has already been identified in 1950 by Bates and Nicolet. Additionally, $\mathrm{OH}$ is important for changing the partitioning of the nitrogen and the halogen family which are crucial for the $\mathrm{O}_{3}$ removal in the stratosphere.

Several studies discussed an increase in stratospheric water vapor (e.g. Evans et al., 1998; Michelsen et al., 2000; Nedoluha et al., 1998; Rosenlof et al., 2001). For example, Rosenlof et al. (2001) combined ten different data sets between 1954 and 2000, and estimated a water vapor trend of $+1 \% / y r$. Several reasons like enhanced methane oxidation, increased aircraft emission in the LS, a warming of the tropical tropopause, volcanic eruptions and largescale changes in stratospheric circulation and tropospherestratosphere-exchange have been discussed, but the observed stratospheric water vapor increase is not yet understood (Evans et al., 1998, and references therein). In contrast, tropical tropopause temperatures have been found to decrease (Zhou et al., 2001).

Oltmans et al. (2000) analyzed 20 years of water vapor measurements with the NOAA Climate Monitoring and Diagnostics Laboratory (CMDL) frostpoint hygrometer over Boulder, $\mathrm{CO}$, and reported a $+1 \% / \mathrm{yr}(+0.05 \mathrm{ppmv} / \mathrm{yr})$ trend

(C) 2005 Author(s). This work is licensed under a Creative Commons License. 


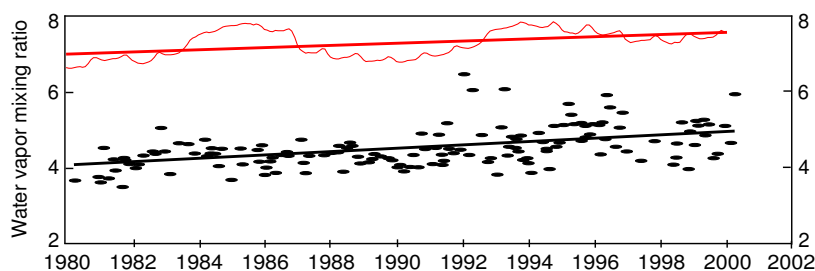

Fig. 1. Time series of individual water vapor soundings with the CMDL frostpoint hygrometer between 24 and $26 \mathrm{~km}$ at Boulder, CO (black) (Oltmans et al., 2000), and of monthly mean water vapor mixing ratios from ECHAM4.L39(DLR)/CHEM at $40^{\circ} \mathrm{N}$, $20 \mathrm{hPa}$ (red) (Dameris et al., 2005). The linear trend with the $95 \%$ confidence interval is $0.044 \pm 0.012 \mathrm{ppmv} / \mathrm{yr}$ for Boulder and $0.029 \pm 0.007 \mathrm{ppmv} / \mathrm{yr}$ for the model simulation.

in the LS. Figure 1 shows a comparison of this time series with a corresponding water vapor time series from a transient model simulation with ECHAM4.L39(DLR)/CHEM (Dameris et al., 2005). Over the 20 year period between 1980 and 1999 both time series show a positive trend. However, over the 40 year period from 1960 to 1999 the model results do not show a sustained positive trend (see Dameris et al., 2005, for further information). The water vapor trend over Boulder $(24-26 \mathrm{~km})$ is $+0.044 \pm 0.012 \mathrm{ppmv} / \mathrm{yr}$ (Oltmans et al., 2000). The simulated water vapor trend is about $35 \%$ weaker, it amounts to $+0.029 \pm 0.007 \mathrm{ppmv} / \mathrm{yr}$ (the given uncertainties are the $95 \%$ confidence intervals using the t-statistic). A current study of Randel et al. (2004) reports a great disparity between the Boulder dataset and HALOE satellite data near Boulder regarding the decadal water vapor changes for the period 19922002. For the period 1992-1996 both datasets show a reasonable agreement. After 1997 the Boulder balloon data further increase in time, while HALOE stays relatively constant, so that HALOE shows small or even negative water vapor trends in the LS for 1992-2002. However, after 2001 both datasets again show a good agreement with remarkably low and persistent water vapor anomalies. Taking into account the above mentioned uncertainties in stratospheric water vapor trends the magnitude of the modeled water vapor increase is comparable with observations. The modeled water vapor increase is mainly associated with a warming of the tropical tropopause, which is in contrast to the observations where water vapor changes and changes of the tropical tropopause temperature are apparently in disagreement, and to some extent $(\approx 30 \%)$ with the methane increase.

Furthermore, the transient model simulation shows a decrease in global mean total ozone that is in agreement with observations (Fig. 2a, for further information see Dameris et al., 2005). Over the 20 year period between 1980 and 1999 the global mean ozone decline amounts approximately $1.7 \% /$ decade (5.5 DU/decade). Several studies have shown that increasing stratospheric water vapor affects the ozone

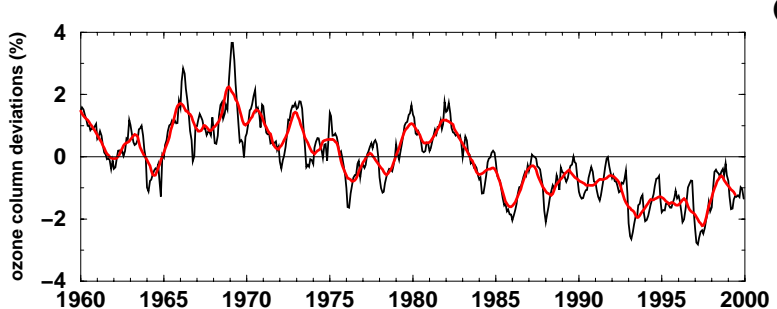

(a)

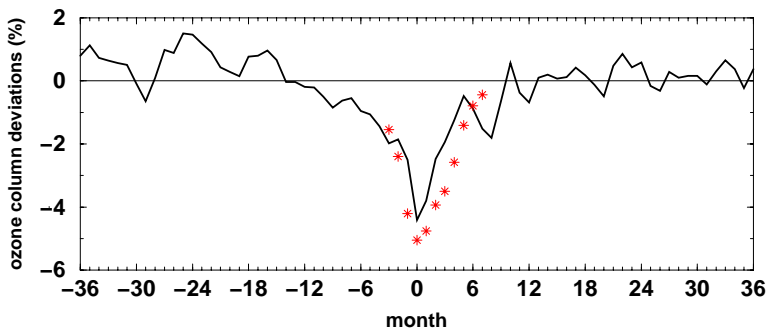

(b)

Fig. 2. (a) Modeled total ozone deviations, deseasonalized with respect to the period 1979-1987 and expressed as percentages of the ground-based time average for the period 1964-1980, area-weighted mean $90^{\circ} \mathrm{N}-90^{\circ} \mathrm{S}$ (see Fioletov et al., 2002, for details of analysis). Red line shows a 13-month running mean. (b) Modeled total ozone deviations within the tropics $\left(10^{\circ} \mathrm{N}-10^{\circ} \mathrm{S}\right)$ averaged over the last three major volcanic eruptions, expressed as percentages of the average for the period 1964-1980. Month 0 indicates the minimum ozone value after the volcanic eruptions. The eruptions occurred between 8 and 23 months earlier. The red stars indicate the estimated reduction of the ozone column caused by the additional uplift during a volcanic period applying a linearized transport-chemistry column model.

budget significantly (e.g. Evans et al., 1998; Dvortsov and Solomon, 2001). One objective of this study is to assess the contribution of the simulated water vapor increase to the analyzed ozone decrease in the above mentioned transient model simulation (Dameris et al., 2005).

Furthermore, the model simulation shows two pronounced water vapor peaks, associated with the eruption of the volcanos El Chichon $\left(17.33^{\circ} \mathrm{N}, 93.20^{\circ} \mathrm{W}\right)$ in 1982 and Mount Pinatubo $\left(15.13^{\circ} \mathrm{N}, 120.35^{\circ} \mathrm{E}\right)$ in 1991 (Fig. 1). Enhanced water vapor mixing ratios are also seen in the Boulder dataset after the Pinatubo eruption in 1992 (Fig. 1). The heating effect of additional volcanic aerosol on the tropical tropopause results in a short-term increase of stratospheric water vapor (Considine et al., 2001). In the model simulation the water vapor mixing ratios return to pre-volcanic levels approximately two years after the maximum value. Since both volcanos are located in the tropics within the upwelling branch of the Brewer-Dobson circulation, it is expected that the gasphase chemistry of the tropical LS is primarily influenced by a short-term increase in the water vapor loading. Figure $2 b$ shows the simulated tropical ozone decline after the last three major volcanic eruptions. Beside the ozone trend analysis mentioned above a second major objective of this study is 
to investigate whether these short-term ozone changes arise from a short-term water vapor increase.

In this paper we investigate the impact of stratospheric water vapor perturbations on ozone chemistry by model simulations with the coupled climate-chemistry model ECHAM4.L39(DLR)/CHEM. We use a special method to prevent a feedback of the simulated water vapor increase to the model dynamics in order to separate the chemical effect. A short model description is given in the next section. Section 3 describes the applied tracer approach. The results of our study are presented in Sects. 4.1 and 4.2, followed by a discussion in Sect. 4.3. A summary is given in the last section.

\section{Model description}

The coupled climate-chemistry model ECHAM4.L39(DLR)/CHEM (Hein et al., 2001, hereafter referred to as E39/C) consists of the dynamic part ECHAM4.L39(DLR) (E39) and the chemistry module CHEM. E39 is a spectral general circulation model, based on the climate model ECHAM4 (Roeckner et al., 1996), and has a vertical resolution of 39 levels up to the top layer centered at $10 \mathrm{hPa}$ (Land et al., 1999). A horizontal resolution of $\mathrm{T} 30\left(\approx 6^{\circ}\right.$ isotropic resolution) is used in this study. The tracer transport, parameterizations of physical processes and the chemistry are calculated on the corresponding Gaussian transform grid with a grid size of $3.75^{\circ} \times 3.75^{\circ}$. Water vapor, cloud water and chemical species are advected by a so-called semi-Lagrangian scheme.

The chemistry module CHEM (Steil et al., 1998) is based on the family concept. It includes stratospheric homogeneous and heterogeneous ozone chemistry and the most relevant chemical processes for describing the tropospheric background $\mathrm{NO}_{\mathrm{x}}-\mathrm{CH}_{4}-\mathrm{CO}-\mathrm{HO}_{\mathrm{x}}-\mathrm{O}_{3}$ chemistry with 107 photochemical reactions, 37 chemical species and 4 heterogeneous reactions (R12-R15) on polar stratospheric clouds (PSCs) and on sulfate aerosols. CHEM does not yet consider bromine chemistry. Mixing ratios of methane $\left(\mathrm{CH}_{4}\right)$, nitrous oxide $\left(\mathrm{N}_{2} \mathrm{O}\right)$ and carbon monoxide $(\mathrm{CO})$ are prescribed at the surface following IPCC (2001) for the year 2000. Zonally averaged monthly mean concentrations of chlorofluorocarbons (CFCs) and upper boundary conditions for total chlorine and total nitrogen are taken from the 2-D model of Brühl and Crutzen (1993). Nitrogen oxide emissions at the surface (natural and anthropogenic sources), from lightning and aircraft are considered. The model set-up follows Hein et al. (2001) except for the total amounts of emissions, lightning $\mathrm{NO}_{\mathrm{x}}$, which is parameterized according to Grewe et al. (2001), and a more detailed sulfate aerosol chemistry.

The model E39/C can be run in two different modes: withand without-feedback. In the without-feedback mode the concentrations of the radiatively active gases $\mathrm{H}_{2} \mathrm{O}, \mathrm{O}_{3}, \mathrm{~N}_{2} \mathrm{O}$, and CFCs calculated by CHEM do not feed back to the radiative scheme of E39. Prescribed climatological mixing ratios of the radiatively active gases are used as input for the radia- tive scheme instead (Hein et al., 2001). Note that the transient model simulation reported by Dameris et al. (2005), on the other hand, was integrated in the with-feedback mode including the chemical feedbacks on radiatively active gases.

\subsection{Model climatology}

The model climatology was extensively validated in Hein et al. (2001). Generally, the model offers a reasonable description of dynamic and chemical processes and of the parameter distributions in the troposphere and LS. In particular, the modeled dynamics in the northern hemisphere LS are in good agreement with observations. The model is able to reproduce the high interannual dynamic variability including the occurrence of stratospheric warmings. The subsidence of air masses inside the arctic polar vortex is also reproduced by the model. However, Hein et al. (2001) have also mentioned some model weaknesses which seem to be linked to a cold temperature bias in the southern hemisphere polar stratosphere. This temperature bias leads to a too cold and too stable polar vortex and, therefore, influences the antarctic ozone chemistry. This "cold-pole" problem is often considered as being an effect of the low model top at $10 \mathrm{hPa}$, but it should be mentioned that this problem is also present in a number of middle atmosphere models (e.g. Pawson et al., 2000). Sometimes, even the use of this kind of models for coupled chemistry-climate simulations is questioned (Austin et al., 1997). Nevertheless, the results of Hein et al. (2001) and further studies of Schnadt et al. (2002) show that CCMs with a model top centered at $10 \mathrm{hPa}$ and an adequate vertical resolution in the UT/LS region are appropriate to investigate chemistry-climate interactions in the LS. Furthermore, a recent inter-comparison of different CCMs by Austin et al. (2003) revealed that low top models reproduce the observed total ozone distribution as well as high top models. Possible effects of the above mentioned model weaknesses on the results of our study will be discussed in the concluding discussion.

\subsubsection{Water vapor}

Figure 3 displays the modeled annual and zonal mean water vapor and methane mixing ratios as well as the zonal mean of the quantity $2 \times \mathrm{CH}_{4}+\mathrm{H}_{2} \mathrm{O}$. The modeled water vapor distribution shows a strong vertical gradient in the tropopause region following the vertical temperature gradient. Minimum water vapor mixing ratios occur right above the tropical tropopause where the temperatures are lowest. Therefore, the model reproduces the observed water vapor distribution in the UT/LS region reasonably. However, the observed meridional water vapor gradient is not adequately represented in the model which is probably caused by numerical diffusion of the advection scheme. As already stated in Hein et al. (2001), modeled stratospheric water vapor mixing ratios are systematically higher than observed (see also 

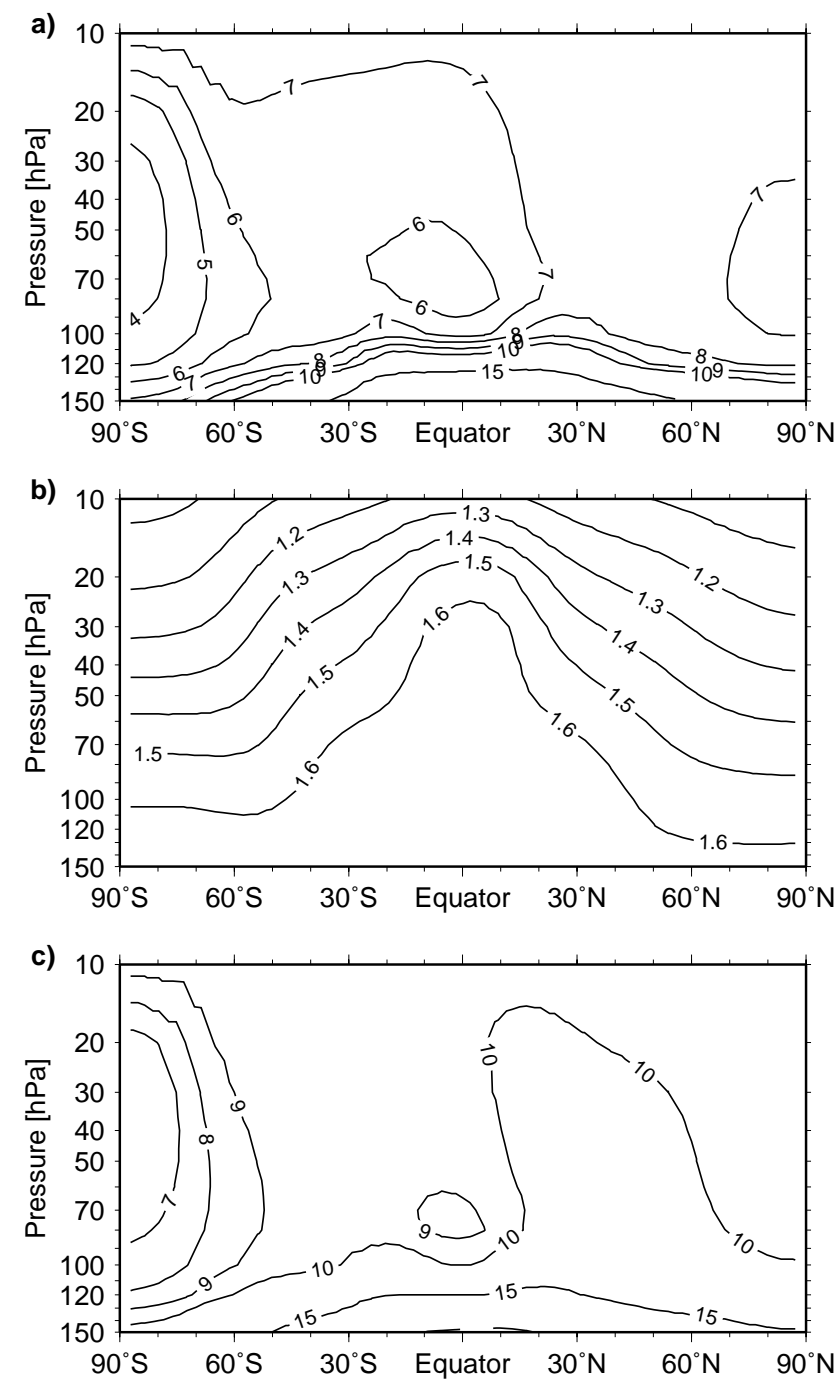

Fig. 3. Annual average of (a) zonal mean water vapor mixing ratios (ppmv), (b) zonal mean methane mixing ratios (ppmv) and (c) zonal mean $2 \times \mathrm{CH}_{4}+\mathrm{H}_{2} \mathrm{O}$ (ppmv). Averaged over the last 10 years (1990-1999) of the transient model simulation (Dameris et al., 2005).

Fig. 1). A comparison between modeled temperatures and ECMWF reanalysis reveals a warm temperature bias near the model's tropical tropopause (Land et al., 1999), which results in enhanced entry level mixing ratios $\left[\mathrm{H}_{2} \mathrm{O}\right]_{\mathrm{e}}$ (modeled: 5.9 ppmv, observed: 3.6-4.1 ppmv; SPARC, 2000). The southern polar stratosphere is characterized by strong dehydration in antarctic winter which is overestimated in the model. This behavior can be directly attributed to the too cold and too stable antarctic polar vortex (Hein et al., 2001).

The modeled methane distribution is shown in Fig. 3b. In the tropics the methane mixing ratio decreases from about $1.65 \mathrm{ppmv}$ to $1.2 \mathrm{ppmv}$ near $10 \mathrm{hPa}$ which is in good agreement with HALOE observations (Rosenlof, 2002). The meridional gradient of methane is slightly underestimated in the model. As mentioned in Hein et al. (2001) this might be taken as an indication for an effect of the low upper boundary.

In order to exclude an upper boundary effect on the modeled water vapor distribution Fig. $3 \mathrm{c}$ shows the zonal mean mixing ratio of the quantity $2 \times \mathrm{CH}_{4}+\mathrm{H}_{2} \mathrm{O}$. The quantity $2 \times \mathrm{CH}_{4}+\mathrm{H}_{2} \mathrm{O}$ should be nearly uniform throughout the stratosphere away from regions of dehydration in the winter polar vortex. The distribution of the quantity $2 \times \mathrm{CH}_{4}+\mathrm{H}_{2} \mathrm{O}$ is dominated by the modeled water vapor distribution. Away from the southern polar region the distribution is nearly constant, whereas northern hemispheric values are slightly higher than in the southern hemisphere which is caused by the water vapor distribution. Figure $3 \mathrm{c}$ does not show a substantial increase of the quantity $2 \times \mathrm{CH}_{4}+\mathrm{H}_{2} \mathrm{O}$ towards the model top. Therefore, an upper boundary effect on the modeled water vapor is not expected.

\subsubsection{Hydroxyl radical}

Since the hydroxyl radical $(\mathrm{OH})$ plays a crucial role for the present study, possible model deficiencies have to be considered. Figure 4 shows a vertical cross-section of the zonally and monthly averaged $\mathrm{OH}$ distribution in E39/C. Because of the extreme variability of $\mathrm{OH}$ in time and space due to the high dependency on the solar zenith angle (Hanisco et al., 2001), in situ OH measurements are not appropriate for model evaluation. Spivakovsky et al. (2000) calculated a global climatological distribution of tropospheric $\mathrm{OH}$ (referred to $\mathrm{OH}_{S p}$ hereafter) using observations of precursors for $\mathrm{OH}$ like $\mathrm{O}_{3}, \mathrm{H}_{2} \mathrm{O}, \mathrm{CO}$, hydrocarbons and $\mathrm{NO}_{\mathrm{t}}$ (defined as $\mathrm{NO}_{2}+\mathrm{NO}+2 \mathrm{~N}_{2} \mathrm{O}_{5}+\mathrm{NO}_{3}+\mathrm{HNO}_{2}+\mathrm{HNO}_{4}$, Spivakovsky et al., 2000) as well as observed temperatures and cloud optical depths as input for a photochemical box model. $\mathrm{OH}_{S p}$ shows the highest zonal mean $\mathrm{OH}$ concentrations in the tropics at ca. $600 \mathrm{hPa}$, peaking at about $25 \times 10^{5}$ molecules $/ \mathrm{cm}^{3}$. Within this altitude range the tropical $\mathrm{OH}$ concentrations in $\mathrm{E} 39 / \mathrm{C}$ are in good agreement with $\mathrm{OH}_{S p}$. The $\mathrm{OH}$ distribution in $\mathrm{E} 39 / \mathrm{C}$ has its maximum closer to the surface. This might be associated with the missing effects of non-methane-hydrocarbons (NMHCs) on $\mathrm{OH}$ in E39/C. OH is depleted over forested tropical continents by the influence of NMHCs (Lawrence et al., 2001). In both $\mathrm{OH}$ distributions the maximum $\mathrm{OH}$ concentrations are shifted to the respective summer hemisphere during January and July, following the position of the sun. During April and October both $\mathrm{OH}$ distributions are mostly hemispherically symmetric. The mid-latitudes exhibit a strong seasonal cycle that is associated with sunlight and water vapor variations. Both $\mathrm{OH}$ distributions show very low $\mathrm{OH}$ concentrations at high latitudes during winter. $\mathrm{OH}_{S p}$ shows a more pronounced vertical gradient between 500 and $100 \mathrm{hPa}$. Hence E39/C slightly overestimates the $\mathrm{OH}$ concentrations in this altitude range. Generally, the comparison of both 

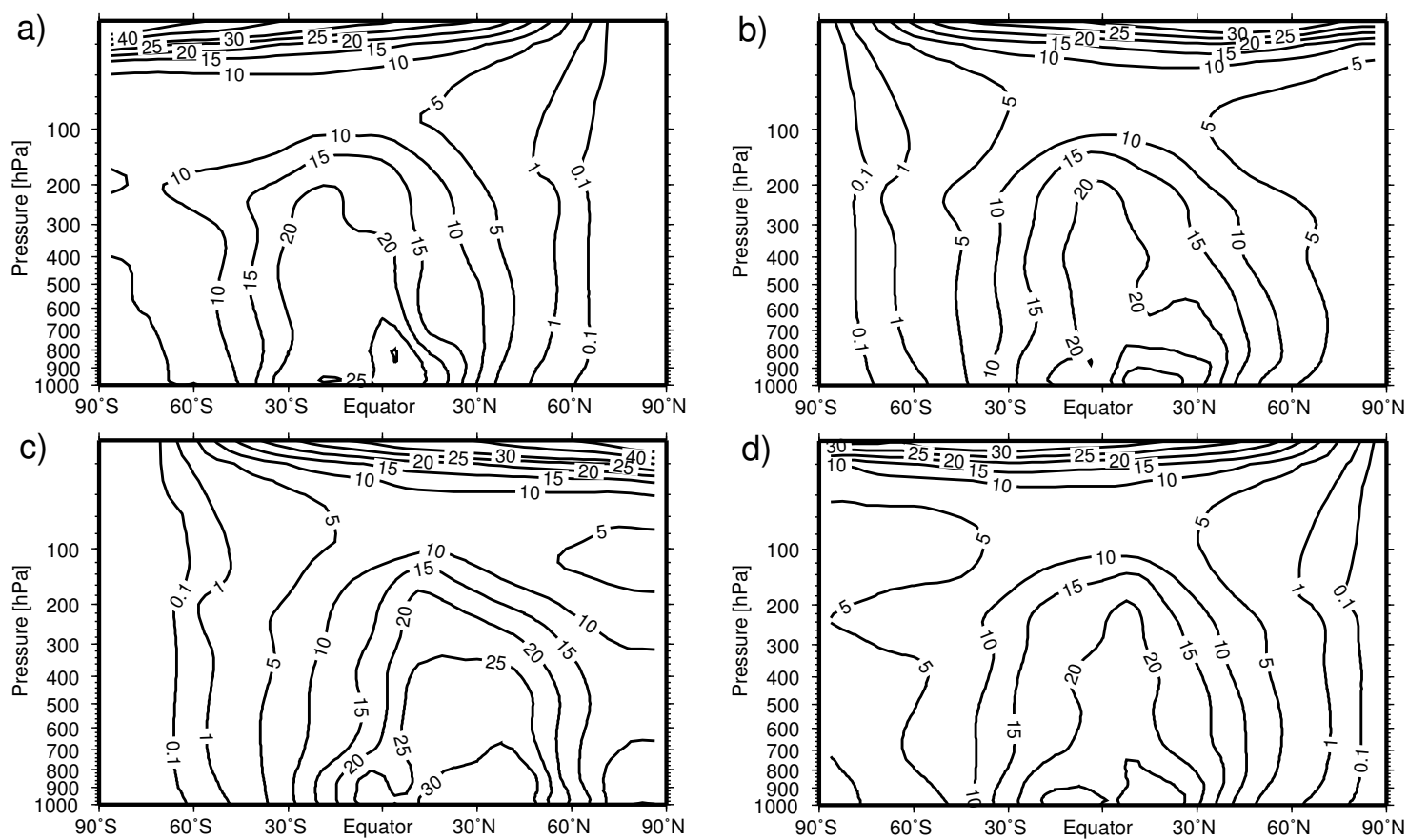

Fig. 4. Zonally and monthly averaged distribution of $\mathrm{OH}\left(10^{5}\right.$ molecules $\left./ \mathrm{cm}^{3}\right)$ for January (a), April (b), July (c) and October (d) as modeled with E39/C. The figure shows a 10-year-climatology, 2000 climate.

Table 1. Overview of analyzed model experiments.

\begin{tabular}{llll}
\hline EXP & feedback mode & $\mathrm{H}_{2} \mathrm{O}$ perturbation & simulation period \\
\hline CNTL & without feedback & 0 ppmv, reference simulation & 11 years \\
VOLC & without feedback & 2 ppmv, July and August, short-term increase & 5 annual cycles July-June (last 5 years of CNTL) \\
H2O_1 & without feedback & 1 ppmv, long-term increase & 11 years \\
H2O_5 & without feedback & 5 ppmv, long-term increase & 11 years \\
\hline
\end{tabular}

$\mathrm{OH}$ distributions shows that for the matter of this study the modeled $\mathrm{OH}$ distribution is realistically enough reproduced.

\section{Methodology}

\subsection{Water vapor perturbations}

Increasing stratospheric water vapor affects atmospheric dynamics as well as the chemical composition of the atmosphere. Either effect contributes to a modified ozone distribution. In turn, the changed ozone distribution again affects atmospheric dynamics. For a better understanding of coupling processes between atmospheric chemistry and dynamics this study investigates the impact of an additional water vapor loading on stratospheric chemistry without changing atmospheric dynamics. Therefore, the model was run without feedback effects of the modeled water vapor increase on model dynamics. For this purpose a special tracer approach was introduced in E39/C: Two water vapor tracers are dis- tinguished - the background water vapor and a water vapor perturbation. The radiative calculations are performed with the background water vapor and the model chemistry is computed with the "chemical" water vapor. The "chemical" water vapor field is defined as follows:

$$
\mathrm{H}_{2} \mathrm{O}_{\text {Chemistry }}=\mathrm{H}_{2} \mathrm{O}_{\text {Background }}+\mathrm{H}_{2} \mathrm{O}_{\text {Perturbation }}
$$

The water vapor perturbation is transported like an arbitrary tracer by the semi-Lagrangian advection scheme of E39/C. In order to treat the water vapor perturbation as realistic as possible it has to pass the same physical source and sink processes as the background water vapor. These processes include convection, condensation and vertical exchange by turbulence. This means, if cloud formation and precipitation cause a reduction of the background water vapor content by $10 \%$ within one model grid box, then the amount of the water vapor perturbation within this grid box is also reduced by $10 \%$. The water vapor perturbation is fixed to a constant value within the tropical LS at each integration time step. 

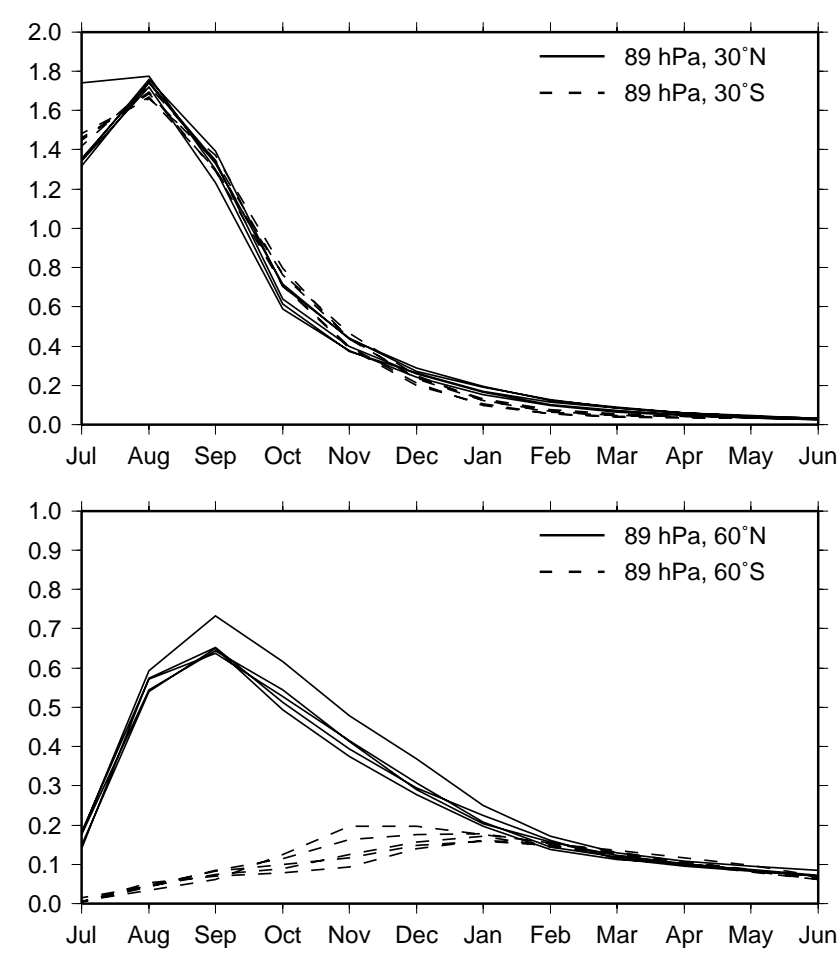

Fig. 5. Five annual cycles of the zonal mean water vapor perturbation (ppmv) at $89 \mathrm{hPa}, 30^{\circ} \mathrm{N} / \mathrm{S}$ (upper panel) and $60^{\circ} \mathrm{N} / \mathrm{S}$ (lower panel) of the simulation VOLC. Solid line: northern hemisphere; dashed line: southern hemisphere.

Below $200 \mathrm{hPa}$ the perturbation field is set to zero since this study concentrates on the stratosphere.

\subsection{Experimental design}

For the current study various model simulations with E39/C were performed. A short overview of the performed simulations is given in Table 1. The model was run in the withoutfeedback mode. Thus, all experiments have identical meteorology. The adopted mixing ratios of greenhouse gases and $\mathrm{NO}_{\mathrm{x}}$ emissions of different sources represent atmospheric conditions of the year 2000 (Tables 2 and 3). The simulations CNTL, H2O_1 and H2O_5 were integrated over 11 years in a quasi-stationary state (time slice simulations). The last five years of the integration period were analyzed. The simulation CNTL was performed without a water vapor perturbation as reference simulation. As mentioned above, this paper deals with two different objectives: 1 . Chemical impact of a short-term increase of stratospheric water vapor after a volcanic eruption. Therefore, an ensemble of five 1-yearsimulations was analyzed, representing the last five years of CNTL (hereafter referred to as VOLC). Each annual cycle starts in July, since the Mount Pinatubo eruption occurred 15 June 1991. During July and August additional water vapor is "emitted" in the tropical lower stratosphere by the above
Table 2. Mixing ratios of greenhouse gases adopted for the year 2000 as recommended by IPCC (2001).

\begin{tabular}{cccc}
\hline $\mathrm{CO}_{2}$ (ppmv) & $\mathrm{CH}_{4}$ (ppmv) & $\mathrm{N}_{2} \mathrm{O}$ (ppbv) & $\mathrm{Cl}_{\mathrm{y}}$ (ppbv) \\
\hline 375 & 1.76 & 316 & 2.7 \\
\hline
\end{tabular}

Table 3. $\mathrm{NO}_{\mathrm{x}}$ emissions adopted for the year $2000\left({ }^{*}\right.$ taking into account IPCC, 2001, rates of increase).

\begin{tabular}{lcl}
\hline $\mathrm{NO}_{\mathrm{x}}$ source & $\begin{array}{c}\text { Global source } \\
(\mathrm{Tg}(\mathrm{N}) / \mathrm{yr})\end{array}$ & Reference \\
\hline Air traffic & 0.7 & Schmitt and Brunner (1997)* \\
Lightning & $\approx 5$ & Grewe et al. (2001) \\
Industry, Traffic & 33.0 & Benkovitz et al. (1996)* \\
Soils & 5.6 & Yienger and Levy (1995)* \\
Biomass burning & 7.1 & Hao et al. (1990)* \\
\hline
\end{tabular}

mentioned method. The water vapor perturbation in the tropical LS is set to 2 ppmv. For the rest of the year the emission is stopped. Five different years were chosen to cover a range of dynamical situations. Figure 5 shows the annual cycle of the water vapor perturbation for the five simulations at $89 \mathrm{hPa}$ at $30^{\circ} \mathrm{N} / \mathrm{S}$ and $60^{\circ} \mathrm{N} / \mathrm{S}$. Within the tropics the perturbation shows a rapid decrease after the peak in August. The e-folding time of the perturbation is 2 months. The variability within the ensemble of five 1-year-simulations is very small. At $30^{\circ}$ the interhemispheric differences are just as little as the differences between the different annual cycles of VOLC. At $60^{\circ}$ the interhemispheric differences are much more pronounced. In the northern hemisphere the perturbation peaks in September whereas the southern hemispheric peak occurs 3 month delayed in December. This pattern indicates a more intense northward transport in the model within the lowermost stratosphere during summer. This transport pattern has also been identified by Grewe et al. (2004) who studied the impact of horizontal transport caused by streamers on the chemical composition of the tropopause region.

2. Chemical impact of a long-term stratospheric water vapor increase. For that purpose two long-term perturbation experiments were performed, $\mathrm{H}_{2} \mathrm{O} \_1$ and $\mathrm{H} 2 \mathrm{O} \_5$. In $\mathrm{H} 2 \mathrm{O} \_5$ the water vapor perturbation in the tropical LS is set to ca. 5 ppmv. This value corresponds roughly to a doubling of water vapor within the LS. This model experiment was designed as a maximum impact scenario. Taking into account a stratospheric water vapor trend of $+0.05 \mathrm{ppmv} / \mathrm{yr}$ the doubling of water vapor would be reached in ca. 100 years. The simulation $\mathrm{H}_{2} \mathrm{O} \_1$ was performed like $\mathrm{H} 2 \mathrm{O} \_5$, but the perturbation was set to 1 ppmv. Figure 6 shows the climatological mean distribution of the water vapor perturbation in $\mathrm{H}_{2} \mathrm{O} \_5$ for January and July. The dark shaded area indicates the "source region" where the perturbation is fixed. 


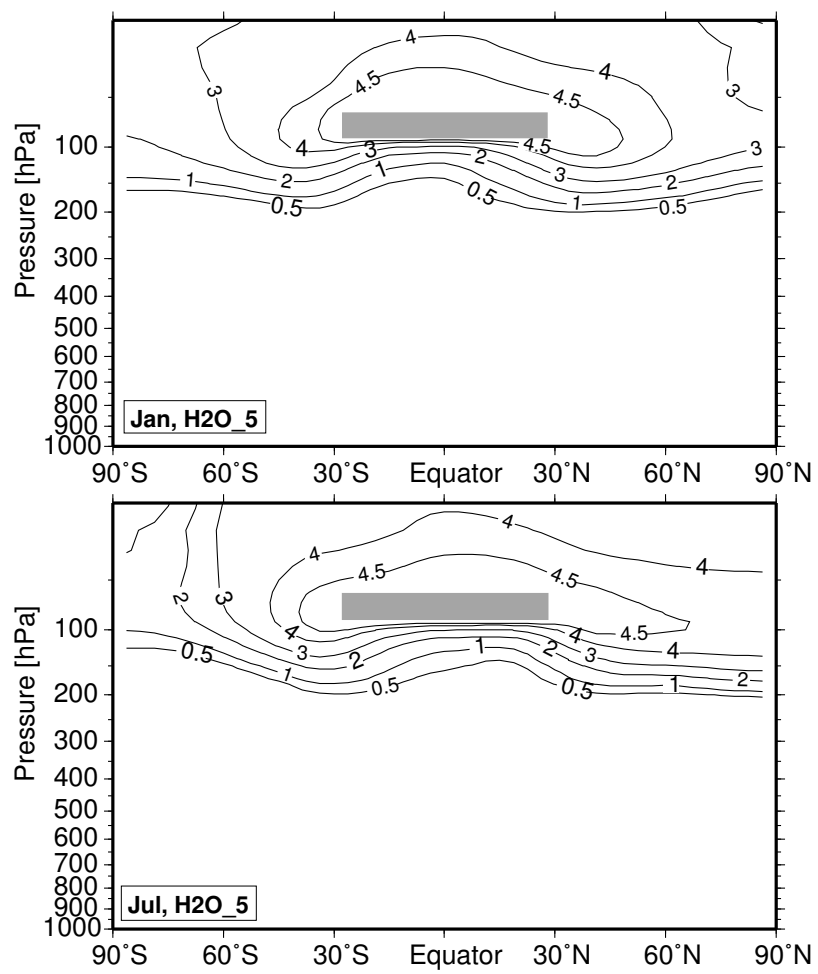

Fig. 6. Zonally averaged volume mixing ratio of the water vapor perturbation (ppmv). This figure displays the mean over 5 analyzed years, simulation $\mathrm{H}_{2} \mathrm{O} \_5$. The gray-shaded area marks the tropical "source region" of the water vapor perturbation.

Approximately $70 \%$ of the tropical perturbation can be found around $70^{\circ} \mathrm{N}(\approx 3.5 \mathrm{ppmv})$, whereas the perturbation is much lower around $70^{\circ} \mathrm{S}$ (southern hemispheric values 15\%-20\% lower than northern hemispheric values). Again, these results indicate a more intense northward transport. The antarctic winter stratosphere is characterized through strong dehydration. The dehydration of the arctic winter stratosphere is less intensive. Generally, the results for simulation $\mathrm{H}_{2} \mathrm{O} \_1$ show the same pattern, just the absolute values are 5 times smaller.

\section{Results}

In this section the impact of a short-term increase of stratospheric water vapor (Sect. 4.1) as well as two different longterm water vapor perturbations (Sect. 4.2) on stratospheric ozone chemistry are analyzed in detail. The description of chemical processes and reactions (see Appendix) is limited to those which are important for this study. A complete description of stratospheric ozone chemistry can be found e.g. in Seinfeld and Pandis (1998).
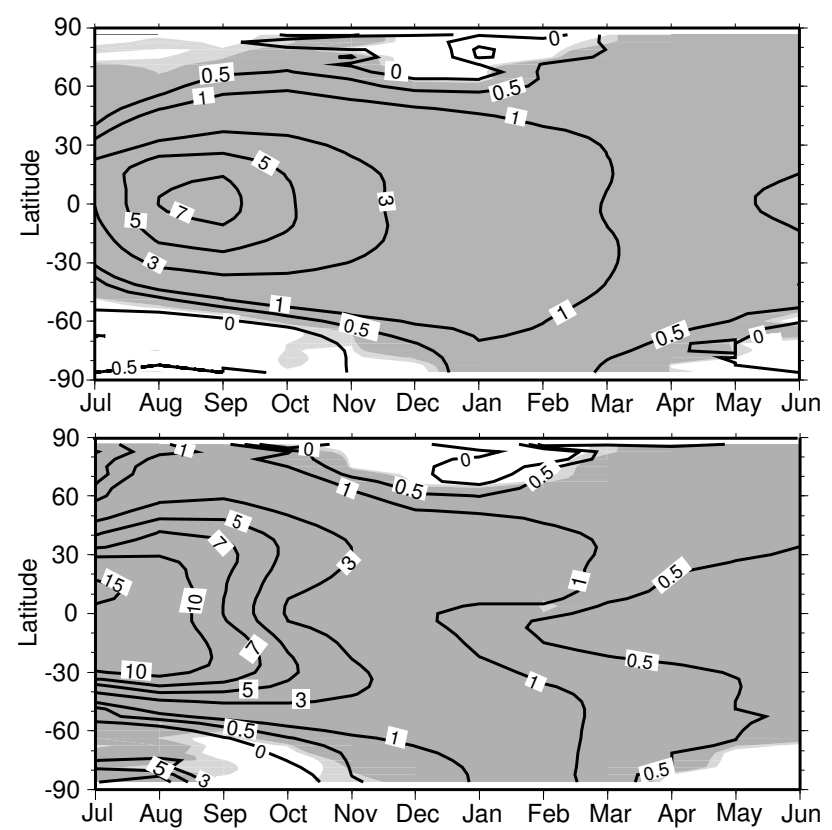

Fig. 7. Relative changes (\%) of zonal mean $\mathrm{OH}$ concentration at $50 \mathrm{hPa}$ (upper panel) and $80 \mathrm{hPa}$ (lower panel) depending on latitude and season, VOLC-CNTL/CNTL. Heavy (light) shaded areas indicate the $99 \%$ (95\%) significance level of the displayed changes ( $t$-test).

\subsection{Short-term increase of stratospheric water vapor}

This section deals with the impact of a short-term increase of stratospheric water vapor as associated with strong volcanic eruptions like the Mount Pinatubo eruption in 1991 (simulation VOLC). It should be pronounced that the impact of the additional volcanic aerosol surface area on ozone chemistry is not taken into account.

Since water vapor is an important source of odd hydrogen (Reaction R1) the short-term water vapor increase results in an enhanced stratospheric $\mathrm{OH}$ concentration. Figure 7 shows the percentage changes of the $\mathrm{OH}$ concentration at $50 \mathrm{hPa}$ (upper panel) and $80 \mathrm{hPa}$ (lower panel) in the VOLC simulation depending on latitude and season. The $\mathrm{OH}$ concentration increases in both hemispheres. The most pronounced changes occur within the tropics associated with the highest $\mathrm{H}_{2} \mathrm{O}$ perturbation. The tropical $\mathrm{OH}$ increase peaks with up to $15 \%$ at $80 \mathrm{hPa}$ in July and with up to $7 \%$ at $50 \mathrm{hPa}$ in August. The $50 \mathrm{hPa}$ level is above the "source" region of the $\mathrm{H}_{2} \mathrm{O}$ perturbation $(\approx 96-70 \mathrm{hPa})$. This indicates that the modeled upward transport within the tropics between 80 and $50 \mathrm{hPa}$ takes about one month. Of special interest are the two peaks at ca. $\pm 30-40^{\circ}$ at $80 \mathrm{hPa}$. This pattern is linked to the polwards and downwards transport of the maximum $\mathrm{OH}$ signal. In contrast, at $50 \mathrm{hPa}$ the maximum is located symmetrically around the equator. The changes within the polar winter regions are not relevant due to the low $\mathrm{OH}$ background concentrations. 

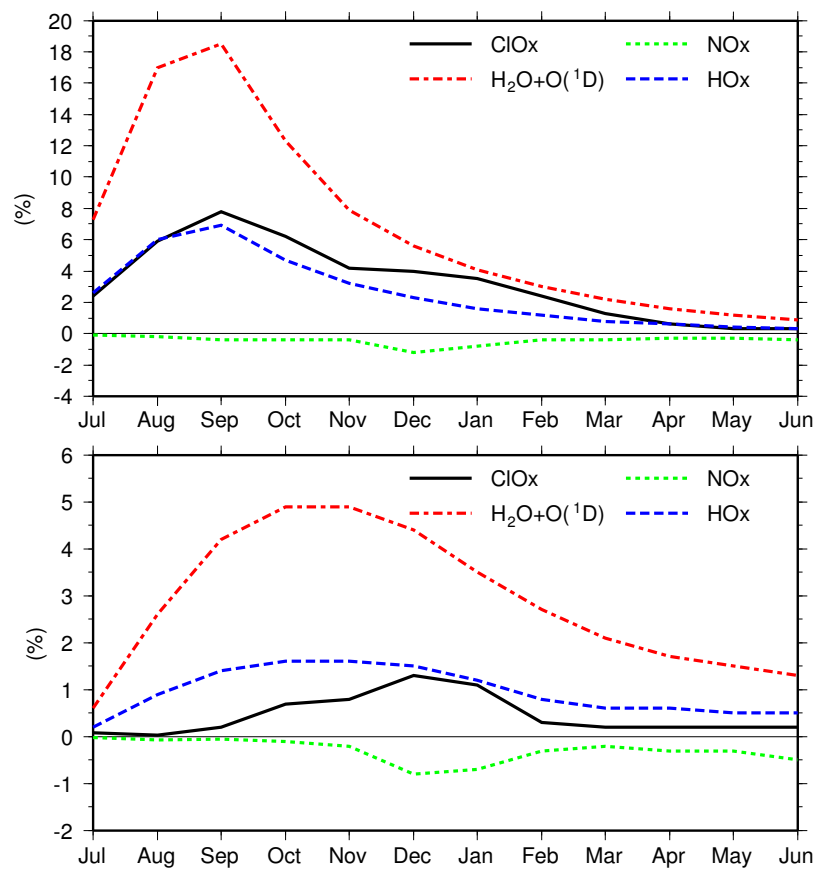

Fig. 8. Percentage increase/decrease of different ozone destroying cycles/reactions in VOLC compared to CNTL at $50 \mathrm{hPa}$. Upper panel: tropics, lower panel: sum of northern and southern midlatitudes $\left(45^{\circ}\right)$.

Changing stratospheric $\mathrm{OH}$ levels affect the different ozone destruction reactions. Figure 8 shows the relative changes of the effectiveness of the $\mathrm{HO}_{\mathrm{x}}, \mathrm{ClO}_{\mathrm{x}}$ and $\mathrm{NO}_{\mathrm{x}}$ cycle (Reactions R3 and R4) as well as of the reaction $\mathrm{H}_{2} \mathrm{O}+\mathrm{O}\left({ }^{1} \mathrm{D}\right) \rightarrow 2 \mathrm{OH}$ (removal of odd oxygen) at $50 \mathrm{hPa}$ and different latitudes (upper panel: tropics, lower panel: mid-latitudes) caused by the stratospheric $\mathrm{OH}$ increase. The background contribution of the different processes to the ozone destruction in CNTL is given in the first row of Table 4, the relative changes of ozone loss rates for August and December are given in rows 3 and 4. The dominant effect of higher water vapor concentrations is the increasing ozone destruction through the $\mathrm{HO}_{\mathrm{x}}$ cycle. Within the tropics the increase of the $\mathrm{HO}_{\mathrm{x}}$ cycle peaks in September with approximately $7 \%$ compared to CNTL. Additionally, the reaction $\mathrm{H}_{2} \mathrm{O}+\mathrm{O}\left({ }^{1} \mathrm{D}\right)$ becomes more effective, but this reaction has only little importance. Enhanced $\mathrm{HO}_{\mathrm{x}}$ levels also change the catalytic effectiveness of $\mathrm{ClO}_{\mathrm{x}}$ and $\mathrm{NO}_{\mathrm{x}}$ cycle. On the one hand, chlorine activation is intensified through Reaction (R6). Reaction (R7) additionally benefits chlorine catalyzed ozone depletion in the LS. As displayed in Fig. 8 the ozone loss through the $\mathrm{ClO}_{\mathrm{x}}$ cycle is slightly intensified. On the other hand, additional $\mathrm{HO}_{\mathrm{x}}$ tends to reduce ozone loss by the $\mathrm{NO}_{\mathrm{x}}$ cycle via Reaction (R5). However, the changes of the $\mathrm{NO}_{\mathrm{x}}$ cycle are negligible $(\leq-1 \%)$. Qualitatively, the mid-latitudes show the same results as the tropics. The changes of the effectiveness are less pronounced than in

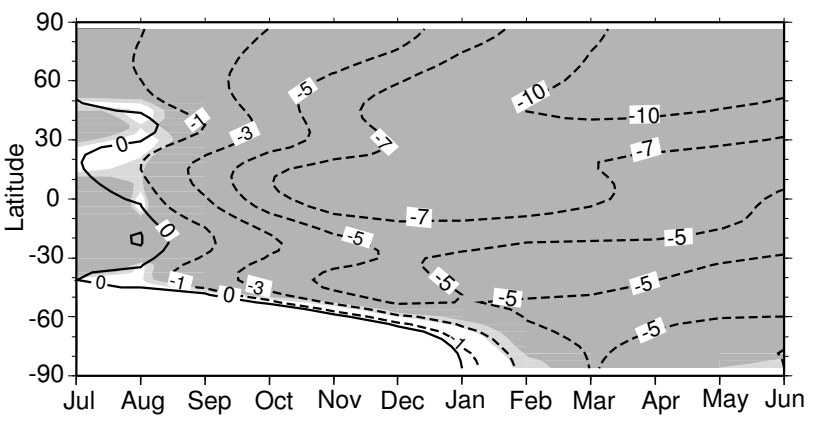

Fig. 9. Relative changes $(0.01 \%)$ of zonal mean total ozone depending on latitude and season, VOLC-CNTL/CNTL. Heavy (light) shaded areas indicate the $99 \%(95 \%)$ significance level of the displayed changes $(t$-test).

the tropics since the $\mathrm{OH}$ increase is less. Additionally, the peaks are slightly shifted to November/December due to the transport times between tropics and mid-latitudes.

The changing ozone destruction yields a global reduction of total ozone except in tropical and mid-latitude regions during July as presented in Fig. 9. The short-term total ozone increase within the tropics during July is associated with an intensified oxidation of methane caused by the additional $\mathrm{OH}$ and the resultant increase in ozone production via Reactions (R8)-(R11). This increased ozone production is restricted to the altitude range $100-80 \mathrm{hPa}$ and compensates the enhanced effectiveness of the $\mathrm{HO}_{\mathrm{x}}$ cycle. The enhanced ozone production is to some extent counterbalanced by a more intensive $\mathrm{NO}_{\mathrm{x}}$ cycle, but the extra ozone production dominates. One month later the water vapor perturbation has also reached higher altitudes, where the ozone depletion by the $\mathrm{HO}_{\mathrm{x}}$ cycle becomes more important. Then, the enhanced ozone destruction by the $\mathrm{HO}_{\mathrm{x}}$ cycle overcompensates the increased ozone production at lower altitudes. Whether a tropical water vapor perturbation leads to ozone loss or ozone production depends on the relative contributions of the above mentioned mechanisms, which are dependent on pressure, latitude and season.

No results are shown for southern high latitudes during antarctic winter and spring in Fig. 9. Right after the initialization of the experiments the model results show an unrealistic $\mathrm{ClONO}_{2}$ increase at the upper boundary in the region of the polar vortex edge. Dynamical reasons for this $\mathrm{ClONO}_{2}$ increase are not possible, since the experiments CNTL and VOLC simulate identical meteorology. Chemical conversion between the individual members of the CIX-family caused by the $\mathrm{OH}$ increase is also very unlikely, since the changes of other chemical species like $\mathrm{HCl}$ or $\mathrm{ClO}_{\mathrm{x}}$ do not show an adequate behavior. Numerical effects of the semi-Lagrangian advection scheme are the most probable explanation for this behavior. In some extreme cases the semi-Lagrangian advection scheme may lead to a counter gradient vertical transport (Grewe et al., 2002). This problem is only present in 
Table 4. Ozone destroying cycles/reactions at $50 \mathrm{hPa}$, different latitudes and seasons. CNTL: Contribution of each reaction to the total ozone destruction [\%]. VOLC, H2O_1 and $\mathrm{H} 2 \mathrm{O} \_5$ : Changes compared to CNTL [\%]. The term $\mathrm{O}_{3}$-Loss includes all ozone destroying reactions considered in E39/C.

\begin{tabular}{lccccccccccc}
\hline & \multicolumn{4}{c}{ Annual Mean, Tropics $\left(5^{\circ} \mathrm{N}-5^{\circ} \mathrm{S}\right)$} & \multicolumn{5}{c}{ Annual Mean, Mid-Latitudes $\left(45^{\circ} \mathrm{N} / \mathrm{S}\right)$} \\
& $\mathrm{O}_{3}$-Loss & $\mathrm{HO}_{\mathrm{x}}$ & $\mathrm{NO}_{\mathrm{x}}$ & $\mathrm{ClO}_{\mathrm{x}}$ & $\mathrm{H}_{2} \mathrm{O}+\mathrm{O}\left({ }^{1} \mathrm{D}\right)$ & $\mathrm{O}_{3}$-Loss & $\mathrm{HO}_{\mathrm{x}}$ & $\mathrm{NO}_{\mathrm{x}}$ & $\mathrm{ClO}_{\mathrm{x}}$ & $\mathrm{H}_{2} \mathrm{O}+\mathrm{O}\left({ }^{1} \mathrm{D}\right)$ \\
\hline CNTL & - & 77.1 & 14.0 & 1.4 & 2.9 & - & 60.8 & 19.6 & 8.4 & 1.4 \\
H2O_1 & +5.1 & +6.4 & -1.6 & +7.8 & +17.0 & +2.4 & +4.1 & -2.2 & +2.7 & +12.7 \\
H2O_5 & +25.8 & +29.0 & -7.7 & +114.9 & +86.0 & +11.0 & +19.0 & -7.0 & +3.4 & +64.0 \\
\hline VOLC (Aug) & +5.0 & +6.0 & -0.2 & +5.9 & +17.0 & +0.6 & +0.9 & -0.07 & +0.03 & +2.6 \\
VOLC (Dec) & +1.8 & +2.3 & -1.2 & +4.0 & +5.6 & +0.9 & +1.5 & -0.8 & +1.3 & +4.4 \\
\hline & \multicolumn{4}{c}{ Arctic } & $\mathrm{Spring}(\mathrm{April}), 80-90^{\circ} \mathrm{N}$ & \multicolumn{5}{c}{ Antarctic Spring $(\mathrm{October}), 80-90^{\circ} \mathrm{S}$} \\
& $\mathrm{O}_{3}$-Loss & $\mathrm{HO}_{\mathrm{x}}$ & $\mathrm{NO}_{\mathrm{x}}$ & $\mathrm{ClO}_{\mathrm{x}}$ & $\mathrm{H}_{2} \mathrm{O}+\mathrm{O}\left({ }^{1} \mathrm{D}\right)$ & $\mathrm{O}_{3}$-Loss & $\mathrm{HO}_{\mathrm{x}}$ & $\mathrm{NO}_{\mathrm{x}}$ & $\mathrm{ClO}_{\mathrm{x}}$ & $\mathrm{H}_{2} \mathrm{O}+\mathrm{O}\left({ }^{1} \mathrm{D}\right)$ \\
\hline CNTL & - & 26.8 & 47.7 & 7.9 & 0.3 & - & 6.7 & 4.0 & 88.7 & 0.07 \\
H2O_1 & -0.9 & +5.6 & -6.7 & +12.4 & +10.5 & +38.9 & -3.4 & -47.4 & +46.4 & +4.3 \\
H2O_5 & -1.5 & +23.3 & -17.5 & +16.5 & +55.7 & +126.6 & -22.8 & -94.9 & +149.1 & +35.9 \\
\hline
\end{tabular}

simulation VOLC. The long-term experiments are not affected.

Interestingly, the most pronounced total ozone reduction takes place at northern high latitudes during spring/early summer. Since the chemical ozone destruction is only slightly enhanced in VOLC during arctic spring this result seems to be associated with the transport of air masses with reduced ozone content from the tropics to northern high latitudes during winter. Grewe et al. (2004) studied the largescale transport of tropical air masses to higher latitudes at pressure levels between $100 \mathrm{hPa}$ and $30 \mathrm{hPa}$ with the climatechemistry model E39/C. Low ozone air masses are transported from the tropics to higher latitudes by wave breaking events, so-called streamers. Grewe et al. (2004) showed that streamers cause a $30 \%(50 \%)$ decrease of ozone at the extratropical tropopause of the summer (winter) hemisphere.

The changes displayed in Fig. 9 are statistically significant although the changes are less than $1 \%$. For this study only the variability of the chemical signal and not the variability of the dynamical signal is used for the $t$-test, taking advantage of the applied methodology (Sect. 3) which leads to identical meteorology in all simulations.

Unfortunately, no observational data are available for the period right after the Mount Pinatubo eruption, suitable for a comparison with model results. Following the volcanic eruption, SAGE II (Stratospheric Aerosol and Gas Experiment) ozone values were systematically overestimated due to the Pinatubo aerosol. SAGE II ozone values below $22 \mathrm{~km}$ altitude are affected by aerosol for approximately 2 years after the Pinatubo eruption (SPARC, 1998). HALOE (Halogen Occultation Experiment) and MLS (Microwave Limb Sounder) satellite data are available since October 1991, i.d. no pre-Pinatubo observations are available for comparison.

\subsection{Long-term increase of stratospheric water vapor}

This section presents the impact of a long-term increase of stratospheric water vapor on stratospheric chemistry as simulated in the model experiments $\mathrm{H}_{2} \mathrm{O} \_1$ and H2O_5. Since the results of both experiments show the same pattern the following figures refer to the simulation $\mathrm{H}_{2} \mathrm{O} \_5$. Figure 10 shows the relative changes of $\mathrm{OH}$ in $\mathrm{H}_{2} \mathrm{O} 55$ compared to the reference simulation CNTL. The zonal mean changes, averaged over 5 years, for July and January are displayed. As expected the additional water vapor results in an elevated stratospheric $\mathrm{OH}$ concentration (Reaction R1). The highest $\mathrm{OH}$ increase occurs in the tropical LS. An additional stratospheric water vapor content of 5 ppmv (1 ppmv) results in a 50\% (10\%) increase in $\mathrm{OH}\left(\approx 20 \times 10^{5}-25 \times 10^{5}\right.$ molecules $/ \mathrm{cm}^{3}, \mathrm{H} 2 \mathrm{O} \_1$ : $\approx 5 \times 10^{5}$ molecules $/ \mathrm{cm}^{3}$ ). Therefore our model results indicate that the $\mathrm{OH}$ response is almost linear related to the stratospheric water vapor perturbation. Since the existence of $\mathrm{OH}$ is coupled to the sunlit atmosphere, $\mathrm{OH}$ background concentrations are very low during the permanent polar night. Therefore the high percentage changes in the winter polar hemispheres are negligible.

Table 4 summarizes the changes of different ozone destroying cycles and reactions at $50 \mathrm{hPa}$ and different latitudes caused by the water vapor perturbation. The first row displays the contribution of the different ozone destroying reactions to the net ozone destruction in the control simulation CNTL. The following two rows display the percentage changes in the perturbation experiments $\mathrm{H}_{2} \mathrm{O}_{-} 1$ and H2O_5 compared to CNTL. The dominating effect is the enhanced effectiveness of the catalytic ozone removal by the $\mathrm{HO}_{\mathrm{x}} \mathrm{cy}-$ cle (Reactions R3-R4). Within the tropics the effectiveness of the $\mathrm{HO}_{\mathrm{x}}$ cycle is $29.0 \%$ (6.4\%) higher in $\mathrm{H} 2 \mathrm{O} \_5$ (H2O_1) than in CNTL. The effectiveness of the $\mathrm{HO}_{\mathrm{x}}$ cycle increases almost linear with the $\mathrm{OH}$ concentration. As 


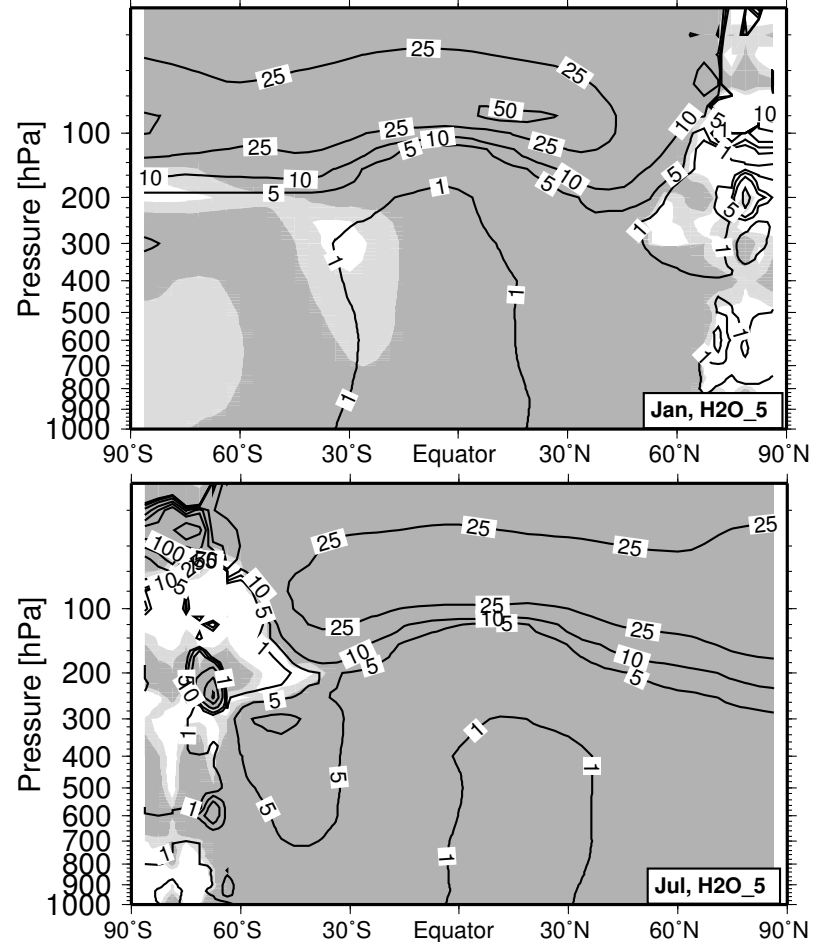

Fig. 10. Zonally and monthly averaged changes of $\mathrm{OH}(\%)$ compared to the simulation CNTL for January and July, simulation H2O_5. Heavy (light) shaded areas indicate the 99\% (95\%) significance level of the displayed changes ( $t$-test).

already mentioned in the previous section enhanced $\mathrm{HO}_{\mathrm{x}}$ levels further facilitates the $\mathrm{ClO}_{\mathrm{x}}$ related ozone destruction (via Reactions R6-R7), whereas the ozone loss through the $\mathrm{NO}_{\mathrm{x}}$ cycle is reduced via Reaction (R5). The changes of the $\mathrm{NO}_{\mathrm{x}}$ cycle and the removal of excited oxygen by the reaction with water vapor also show a linear behavior with increasing $\mathrm{OH}$. The last mentioned process plays only a minor role in the ozone destruction. In contrast, the $\mathrm{ClO}_{\mathrm{x}}$ cycle shows a strong non-linear behavior. The $\mathrm{ClO}_{\mathrm{x}}$ cycle is $7.8 \%$ more effective in $\mathrm{H}_{2} \mathrm{O} \_1$, but above $100 \%$ more effective in H2O_5. However, the contribution of the $\mathrm{ClO}_{\mathrm{x}}$ cycle in the tropics is very small. Within the mid-latitudes the different ozone destruction cycles show qualitatively the same pattern except the $\mathrm{ClO}_{\mathrm{x}}$ cycle which increases only slightly with increasing $\mathrm{OH}$.

As already stated the $\mathrm{OH}$ increase does not only affect ozone destruction, it also results in an enhanced ozone production in the methane oxidation chain (Reactions R8-R11). Furthermore, as stratospheric ozone declines, ultraviolet radiation penetrates deeper into the stratosphere which leads to an enhanced ozone production by the Chapman mechanism. This process affects mainly the tropical LS, but the ozone production by the Chapman mechanism is only slightly enhanced (less than 5\% in H2O_5). However, the increased ozone production can not compensate the enhanced ozone destruction.
The above mentioned results deal with gas-phase chemistry and do not consider heterogeneous reactions on polar stratospheric clouds (PSCs). PSCs occur between 15 and $25 \mathrm{~km}$ at temperatures below $\approx 195 \mathrm{~K}$ (pressure dependent) and promote the release of active chlorine from the reservoir species $\mathrm{HCl}$ and $\mathrm{ClONO}_{2}$. At sunrise, activated chlorine compounds are easily photolyzed and catalytic ozone destruction starts. CHEM uses the classical theory of Hanson and Mauersberger (1988) for the formation of PSCs, based on modeled temperatures and mixing ratios of $\mathrm{HNO}_{3}$ and $\mathrm{H}_{2} \mathrm{O}$, and differentiates between PSCs Type I (NAT, nitric acid trihydrate) and PSCs Type II (ice). Four heterogeneous reactions on PSCs and sulfate aerosols (Reactions R12-R15) are considered in CHEM.

Increases in the concentration of stratospheric water vapor raise the saturation temperature for the formation of PSCs (Kirk-Davidoff et al., 1999). In present conditions, $50 \mathrm{hPa}$ and water vapor mixing ratios of $5 \mathrm{ppmv}$, the saturation temperature for PSCs Type II is about $188.4 \mathrm{~K}$ (calculated according to Salby, 1996). A stratospheric water vapor increase of 3 ppmv, as modeled in H2O_5 in polar regions, raises the saturation temperature to $191.2 \mathrm{~K}(50 \mathrm{hPa})$. Whether the higher saturation temperature results in an intensified PSC activity depends on the simulated temperatures. It should be pronounced that the model simulations H2O_1 and $\mathrm{H}_{2} \mathrm{O} \_5$ do not include any water vapor effects on stratospheric dynamics, in particular stratospheric temperatures. Figure 11 shows 10 different annual cycles of zonal mean temperatures at $80^{\circ} \mathrm{N}, 50 \mathrm{hPa}$ (left) and $80^{\circ} \mathrm{S}, 50 \mathrm{hPa}$ (right) from the reference simulation CNTL. The black lines indicate the saturation temperature at normal and increased water vapor mixing ratios of 5 ppmv (188.4 K) and 8 ppmv (191.2 K), respectively. In the northern hemisphere polar stratosphere, the modeled temperatures hardly ever reach the saturation threshold for normal conditions (188.4 K). Even in the case of increased water vapor mixing ratios the modeled temperatures fall rarely below the saturation temperature (191.2 K). Therefore, the additional water vapor content might affect the PSCs activity in the arctic polar vortex during single, very cold events, but the model results do not indicate a significant impact on the PSCs formation in general.

In the southern hemisphere, Fig. 11 shows a different pattern. Associated with the cold temperature bias in the polar stratosphere modeled temperatures fall below the saturation temperature during the whole antarctic winter period between June and September/October. The additional water vapor content yields an extention of the "PSC-period" by approximately two weeks (indicated by the light shaded areas in Fig. 11) as well as to an increase in the PSC surface area. Although the cold temperature bias leads to a too long PSC existence time, the effect of an extension of the PSCperiod caused by the water vapor increase is not affected by this bias, since the observed temperatures are already below the saturation temperature. The "observed" extension of the PSC period may even be more sensitive to water vapor 

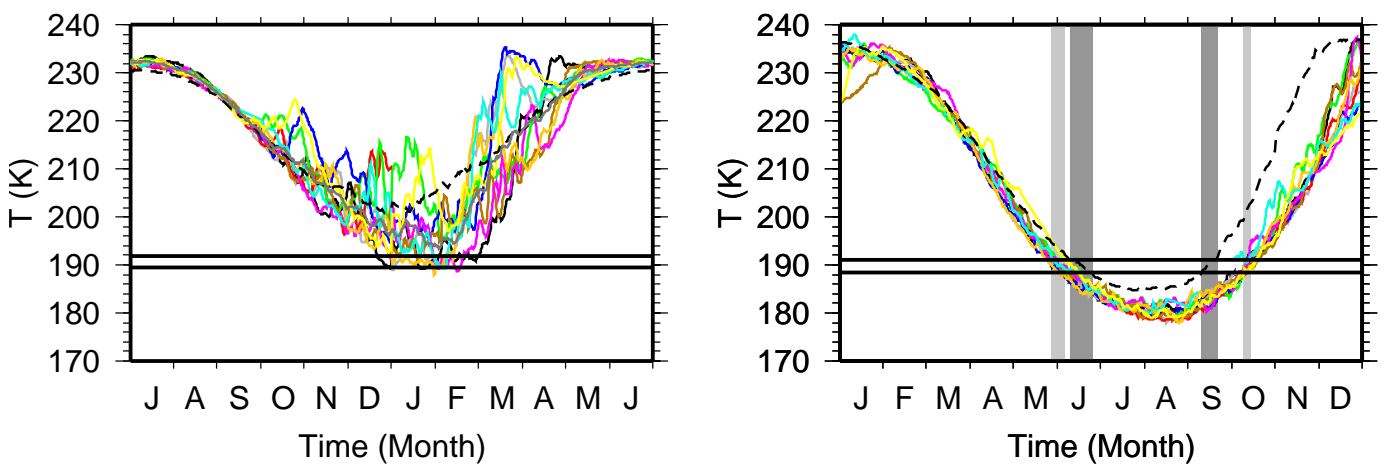

Fig. 11. Modeled temperature at $80^{\circ} \mathrm{N}, 50 \mathrm{hPa}$ (left) and $80^{\circ} \mathrm{S}, 50 \mathrm{hPa}$ (right) from the reference simulation CNTL. The colors indicate 10 different model years. The dashed lines indicate mean analyzed temperatures based on long-term observations (1979-2004) from the National Center for Environmental Prediction (NCEP, data can be accessed via http://hyperion.gsfc.nasa.gov). The black lines mark the saturation temperature at water vapor mixing ratios of 5 ppmv $(188.4 \mathrm{~K})$ and 8 ppmv $(191.2 \mathrm{~K})$. The gray shaded areas indicate the extension of the PSC existence period associated with the raised saturation temperature (light: E39/C, dark: NCEP reanalysis).

changes, since the temperature changes are smaller in JuneJuly-August compared to March and October (indicated by the dark shaded areas in Fig. 11).

In contrast to the formation of PSCs Type II, which depends on temperature and water vapor mixing ratios, the formation of PSCs Type I additionally depends on the mixing ratio of $\mathrm{HNO}_{3}$. The model results indicate a small increase of PSCs Type I in the early winter of the northern (November) as well as the southern hemisphere (May) associated with the additional water vapor (not shown). This enhanced PSC activity intensifies the denitrification of the polar stratosphere in early winter which results in a slightly less NAT formation during the remaining winter. Nevertheless, the dominating effect in the southern polar stratosphere is the enhanced formation of PSCs Type II. In the northern hemisphere no significant increase in PSC surface area is detected.

Table 4 displays the percentage changes of the different ozone destruction rates at $50 \mathrm{hPa}$ in polar regions during spring. The model results show a remarkable interhemispheric difference: The additional water vapor yields an increase in ozone loss during antarctic spring by $\approx 39 \%$ in simulation $\mathrm{H} 2 \mathrm{O} \_1$ and $\approx 127 \%$ in simulation H2O_5, whereas the spring-time ozone loss in the arctic stratosphere stays nearly constant. The most important changes during antarctic spring concern the $\mathrm{ClO}_{\mathrm{x}}$ cycle which is the most important ozone destruction cycle during antarctic spring. The enhanced PSC activity during antarctic winter intensifies chlorine activation and results in a pronounced ozone loss through the $\mathrm{ClO}_{\mathrm{x}}$ cycle in spring $\left(+47 \%\right.$ in $\mathrm{H}_{2} \mathrm{O} \_1,+150 \%$ in H2O_5). Additionally, it leads to an enhanced denitrification of the antarctic stratosphere which further supports chlorine catalyzed ozone destruction (no re-formation of $\mathrm{ClONO}_{2}$ ). Associated with the denitrification the $\mathrm{NO}_{\mathrm{x}}$ cycle becomes $\approx 50 \%$ less effective in $\mathrm{H}_{2} \mathrm{O} \_1$ and is almost vanished in $\mathrm{H} 2 \mathrm{O} \_5$. Finally, the ozone loss through the $\mathrm{HO}_{\mathrm{x}}$ cycle is slightly reduced, but this effect is less important. In con- trast, the additional stratospheric water vapor has no impact on PSC activity and heterogeneous ozone destruction during northern polar spring. The ozone destruction rate in general remains nearly unchanged, but the contribution of the different ozone destroying reactions is shifted with more effective $\mathrm{HO}_{\mathrm{x}}$ and $\mathrm{ClO}_{\mathrm{x}}$ cycles and a less effective $\mathrm{NO}_{\mathrm{x}}$ cycle.

As a result of the above mentioned processes stratospheric ozone concentrations decrease almost everywhere. Figure 12 displays the ozone changes determined by the differences of the zonal mean climatological ozone volume mixing ratio between the simulations H2O_5 and CNTL for January and July. The strongest ozone reductions occur in polar regions of the LS. In the respective winter hemisphere the maximum ozone reduction is located between 150 and $120 \mathrm{hPa}$. In the respective summer hemisphere the most pronounced changes occur between 120 and $80 \mathrm{hPa}$. In the southern polar stratosphere the ozone reduction in simulation H2O_5 (H2O_1) peaks at $10 \%(3 \%)$. In the arctic stratosphere the maximum ozone decline amounts to $7 \%(1 \%)$. Tropospheric changes do not exceed $1 \%$.

The change of total ozone between the simulations H2O_5 and CNTL is presented in Fig. 13. In the tropics and the northern hemisphere the pattern is very uniform without any seasonal variability. As expected, the most pronounced total ozone reductions occur during southern polar spring with 15\% (H2O_5) and 3\% (H2O_1), respectively. Figure 13 clearly shows the above mentioned interhemispheric difference in spring-time ozone loss: The model results indicate a strong total ozone decline during antarctic spring associated with the additional stratospheric water vapor. In contrast, the model results do not show a similar pattern during arctic spring. The southern polar ozone decline is not statistically significant during September/October and December/January. This feature is associated with the seasonal variability of the modeled temperatures in polar regions (see Fig. 11). The duration as well as the beginning of the 


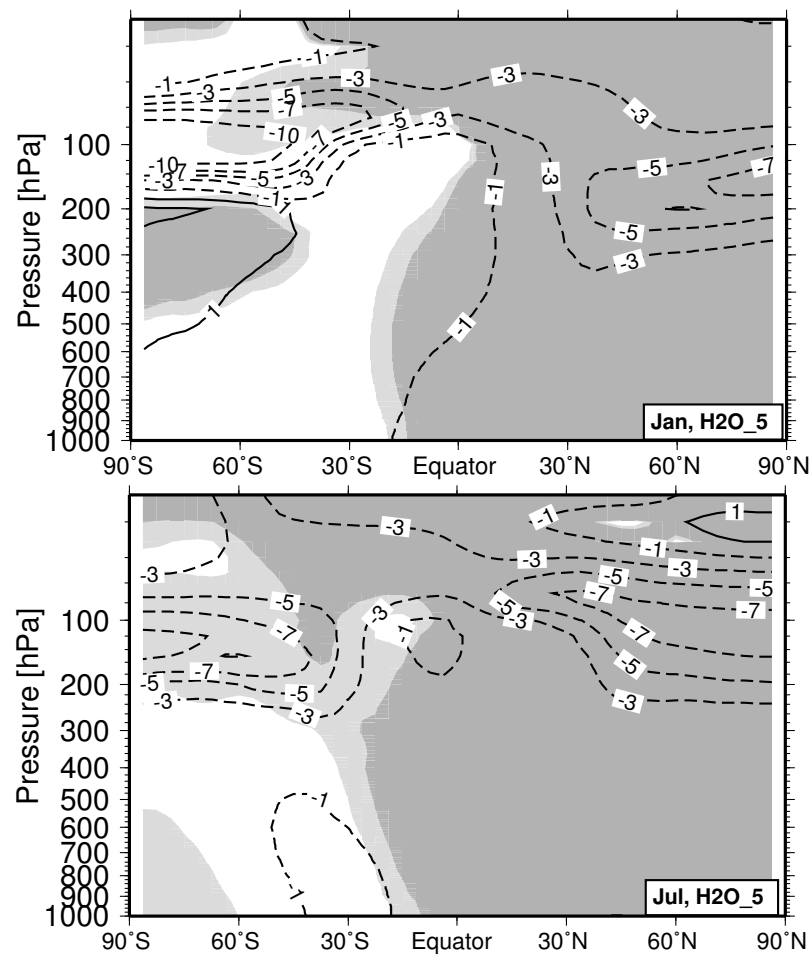

Fig. 12. Zonally and monthly averaged changes of $\mathrm{O}_{3}(\%)$ compared to the simulation CNTL for January and July, simulation H2O_5. Heavy (light) shaded areas indicate the 99\% (95\%) significance level of the displayed changes ( $t$-test).

PSC-period in the antarctic winter LS varies from year to year, resulting in a non-uniform ozone depletion pattern. A comparison between simulation $\mathrm{H}_{2} \mathrm{O} \_1$ and $\mathrm{H} 2 \mathrm{O} \_5$ reveals a nearly linear ozone response to the stratospheric water vapor perturbation (not shown).

\subsection{Discussion}

The analysis of the model simulation VOLC (see Sect. 4.1) indicates an almost negligible impact of short-term water vapor perturbations on total ozone in the tropics (Fig. 9). Therefore, the short-term ozone decline after volcanic eruptions of $\approx 4 \%$ as modeled in the transient model simulation (Fig. 2b) can not only be explained through the short-term water vapor increase. The additional volcanic aerosol heats the stratosphere and amplifies tropical ascent by roughly $20 \%$, leading to an additional uplift during a volcanic period of roughly $1.2 \mathrm{~km}$, which compares reasonably with the uplift of the Pinatubo aerosol cloud by 1.8 km (DeFoor et al., 1992; Kinne et al., 1992). Applying a linearized transport-chemistry column model and using E39/C values for uplift, ozone production and destruction rates of ozone, the simulated vertical ozone profile can be reproduced within 5 to $25 \%$ accuracy. Introducing an additional uplift of $1.2 \mathrm{~km}$ over 8 months produces a vertical displacement of the ozone pro-

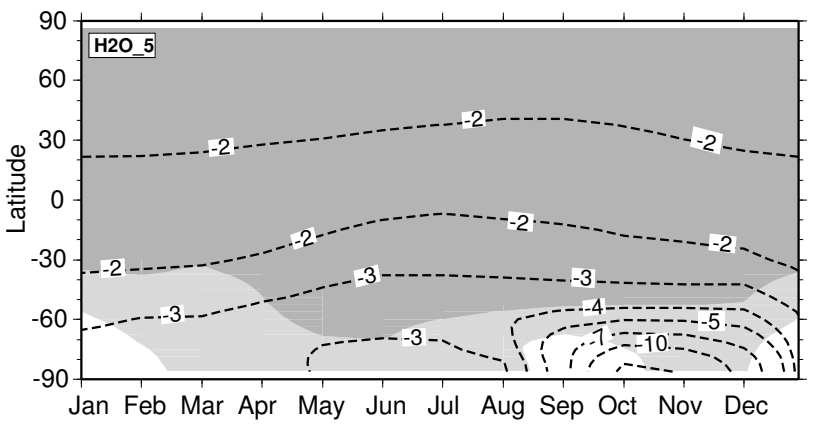

Fig. 13. Relative changes (\%) of climatological zonal mean total ozone depending on latitude and season, simulation $\mathrm{H}_{2} \mathrm{O}_{-} 5-$ CNTL/CNTL. Heavy (light) shaded areas indicate the 99\% (95\%) significance level of the displayed changes ( $t$-test).

file and a reduction of the ozone column of 5\% (red stars in Fig. 2b), agreeing well with the findings of Kinne et al. (1992). This indicates that the ozone decline simulated after volcanic eruptions (Fig. 2b) is dominated by dynamic effects.

A comparison between the simulated short-term (VOLC) and long-term water vapor perturbations (H2O_1 and $\mathrm{H} 2 \mathrm{O} \_5$ ) reveals various differences. VOLC shows a small increase in total ozone within the tropics during July and August. During this period of the simulation VOLC the water vapor perturbation is not yet evenly distributed and the $\mathrm{OH}$ increase is concentrated on the lowermost stratosphere, resulting in a total ozone increase caused by an enhanced ozone production in the methane oxidation chain (Reactions R8-R11). Later on the water vapor perturbation and the associated $\mathrm{OH}$ increase reach higher altitudes where the $\mathrm{HO}_{\mathrm{x}}$ cycle becomes more important. At that time the enhanced ozone loss through the $\mathrm{HO}_{\mathrm{x}}$ cycle dominates over the enhanced ozone production in the lowermost stratosphere, resulting in a total ozone reduction. The model simulations H2O_1 and H2O_5 do not show a similar total ozone increase since the water vapor perturbation has reached a steady distribution and the raised ozone loss through the $\mathrm{HO}_{\mathrm{x}}$ cycle is the dominating effect. Furthermore, simulation VOLC as well as simulation $\mathrm{H}_{2} \mathrm{O}$ 1 1 show a $7 \%$ increase in $\mathrm{OH}$ at $50 \mathrm{hPa}$ within the tropics during August. Despite similar water vapor and $\mathrm{OH}$ perturbations VOLC and $\mathrm{H}_{2} \mathrm{O} \_1$ show different ozone changes within this region. The ozone reduction in $\mathrm{H}_{2} \mathrm{O} \_1$ amounts to $1 \%$, but only $0.07 \%$ in VOLC. At this altitude the ozone concentration is dynamically controlled (Seinfeld and Pandis, 1998, p. 170). Thus, the effect of a short-term change in local chemistry is less important than the impact of a long-term change resulting in different ozone transport.

In a previous study Dvortsov and Solomon (2001) analyzed the response of stratospheric temperatures and ozone to past and future increases in stratospheric humidity $(1 \% / \mathrm{yr})$ with a 2-D radiative-chemical-dynamical model, also separating the radiation effects of water vapor trends on ozone from the photochemical effects. The study of Dvortsov and 
Solomon (2001) concentrated on ozone changes at northern mid-latitudes, water vapor effects on PSC formation and heterogeneous chemistry in polar regions have not been considered. Their results show an additional depletion of midlatitude total ozone of $0.2 \% /$ decade caused by the stratospheric water vapor increase. In this regard our results are in good agreement with the findings of Dvortsov and Solomon (2001).

The effect of increasing stratospheric water vapor on ozone chemistry has also been discussed within the scope of supersonic aircraft emission studies. Within IPCC (1999) the effects of a future (year 2015) supersonic aircraft fleet (500 aircraft) on stratospheric $\mathrm{O}_{3}, \mathrm{H}_{2} \mathrm{O}$ and other species was conducted with various 2-D and 3-D CTMs (chemistry transport model). The maximum $\mathrm{H}_{2} \mathrm{O}$ perturbations caused by supersonic aircraft emissions occurred in the northern hemisphere LS $(\approx 20 \mathrm{~km})$ with values between $0.4 \mathrm{ppmv}$ and $0.7 \mathrm{ppmv}$. The calculated total ozone reduction averaged over the northern hemisphere was in the range between 0.3 and $0.6 \%$. This scenario included only $\mathrm{H}_{2} \mathrm{O}$ emissions, $\mathrm{NO}_{\mathrm{x}}$ emissions were excluded $\left(\mathrm{EI}\left(\mathrm{NO}_{\mathrm{x}}\right)=0\right)$. Performing further scenarios with different $\mathrm{EI}\left(\mathrm{NO}_{\mathrm{x}}\right)$ all models predicted that the most significant supersonic impact on ozone is caused by the water vapor emissions and that the addition of $\mathrm{NO}_{\mathrm{x}}$ emissions leads to less ozone depletion (IPCC, 1999). The modeled water vapor perturbation in $\mathrm{H}_{2} \mathrm{O}_{-} 1$ in the northern hemisphere LS $(\approx 50 \mathrm{hPa}$ ) range from $0.5 \mathrm{ppmv}$ to $0.8 \mathrm{ppmv}$, depending on season (Fig. 6). The resulting total ozone reduction averaged over the northern hemisphere is $\approx 0.5 \%$. In this respect the results of H2O_1 are within the range of IPCC (1999).

\section{Conclusions}

The impact of different idealized stratospheric water vapor perturbations on the stratospheric ozone chemistry without any feedback on atmospheric dynamics was studied with the coupled climate-chemistry model ECHAM4.L39(DLR)/CHEM. To prevent any feedback of the modeled water vapor perturbations a special tracer approach was applied, differentiating between a background water vapor field and the water vapor perturbation. Two different long-term perturbations (+1 ppmv and +5 ppmv) as well as a short-term increase ("volcanic eruption", +2 ppmv, 2 month e-folding time) of stratospheric water vapor were simulated. The impact of water vapor perturbations on the effectiveness of different ozone destroying reactions as well as coupling effects between different chemical processes were analyzed in detail.

A stratospheric water vapor increase leads to an enhanced $\mathrm{OH}$ concentration which results primarily in an enhanced ozone depletion by the $\mathrm{HO}_{\mathrm{x}}$ cycle. The coupling of the $\mathrm{HO}_{\mathrm{x}}$ cycle with the $\mathrm{NO}_{\mathrm{x}}$ and $\mathrm{ClO}_{\mathrm{x}}$ cycle leads to a less effective $\mathrm{NO}_{\mathrm{x}}$ cycle and a slightly enhanced effectiveness of the $\mathrm{ClO}_{\mathrm{x}}$ cycle. Furthermore, increasing stratospheric water vapor concentrations raise the saturation temperature of
PSCs by $0.8 \mathrm{~K} / \mathrm{ppmv}$ (at $50 \mathrm{hPa}, \approx 6 \mathrm{ppmv} \mathrm{H}_{2} \mathrm{O}$ ) (KirkDavidoff et al., 1999). Therefore, a stratospheric water vapor increase is supposed to enhance PSCs activity and heterogeneous ozone loss. In this regard the model results have indicated a strong asymmetry between arctic and antarctic regions: Within the antarctic polar vortex the increase in stratospheric water vapor causes an enhanced PSC formation. Associated with the higher PSC activity the release of active chlorine from reservoir species is intensified which leads to a more effective heterogeneous ozone destruction through the $\mathrm{ClO}_{\mathrm{x}}$ cycle. In contrast, the simulated stratospheric water vapor increase does not affect PSC formation in the arctic stratosphere during winter. This interhemispheric difference is linked to the modeled stratospheric temperatures in the two polar regions. In the arctic polar vortex modeled temperatures fall rarely below the saturation temperature, even in case of the raised saturation temperature. In the southern hemisphere polar vortex the modeled temperatures are generally lower than in the northern hemisphere polar vortex and fall below the saturation temperature during the whole winter. Therefore, the additional stratospheric water vapor yields an extention the PSC-period by two weeks and an increase in PSCs surface area. The simulated short-term water vapor perturbation does not affect PSCs activity and heterogeneous ozone chemistry.

A comparison with NCEP (National Center for Environmental Prediction) reanalysis shows that the modeled temperatures in the northern polar stratosphere are generally in good agreement with the NCEP data, only the mean winter minimum temperature is slightly lower $(\approx 3 \mathrm{~K})$ in the model (Hein et al., 2001, see also Fig. 11). Regarding to the NCEP data the temperatures in the northern polar stratosphere do not fall below the PSC Type II formation temperature during winter. Therefore, neglecting any radiation effect of the water vapor increase, an increase in stratospheric water vapor is not to be expected to cause a general increase in PSC activity and heterogeneous ozone loss in the northern polar stratosphere. To cause a significant increase in PSC activity a strong cooling of the arctic stratosphere would be necessary. However, the magnitude of stratospheric cooling caused by increasing greenhouse gases as well as the contribution of increasing stratospheric water vapor is still unclear (WMO, 2003, chapter 3).

In the southern hemisphere polar stratosphere the modeled mean winter temperature is significantly lower $(\approx 10 \mathrm{~K})$ than in the NCEP data (Hein et al., 2001, see also Fig. 11). However, the observed temperatures also fall below the formation temperature for PSC Type II between June and $\mathrm{Au}-$ gust. Therefore, it is to be expected that an increase in stratospheric water vapor results in an enhanced PSC Type II formation in the southern polar stratosphere. The raised PSC formation temperature may even lead to a larger extension of the PSC existence period than modeled (indicated by the gray shaded areas in Fig. 11), because the temporal temperature changes at the end and beginning of PSC existence time are 
larger in the model simulation than in the observations. The expected radiation effect of a water vapor increase (Forster and Shine, 1999, 2002) would further extend the PSC period. However, the magnitude of the resulting ozone loss depends not only on water vapor concentrations and PSC activity, but e.g. also on the stratospheric chlorine and bromine loading. For example, a model study of Schnadt et al. (2002) on the future chemical composition and climate has shown a slight increase in antarctic ozone depletion due to larger PSC activity, despite a reduced stratospheric chlorine loading.

A comparison between the two different long-term water vapor perturbations ( $\mathrm{H}_{2} \mathrm{O}_{-} 1$ and $\mathrm{H}_{2} \mathrm{O} \_5$ ) has shown that the ozone reduction increases almost linearly with increasing stratospheric water vapor. This linear ozone response agrees well with the results of Dvortsov and Solomon (2001) who also found a linear relationship between ozone response and water vapor perturbation. The results of a transient model simulation (Dameris et al., 2005) with a modeled water vapor increase of $0.029 \mathrm{ppmv} / \mathrm{yr}$ between 1980 and 1999 (Fig. 1) correspond to a stratospheric water vapor perturbation of approximately $0.6 \mathrm{ppmv}$. According to the linear behavior of the ozone response, at least on hemispheric scales, a perturbation of $0.6 \mathrm{ppmv}$ leads to a global total ozone reduction of $0.5 \%$. The simulated global ozone decline between 1980 and 1999 amounts 3.4\%, considering the increasing chlorine loading and climate change. Therefore, the results of this study indicate that $10 \%$ of the ozone decline in the transient model run is linked to the simulated water vapor increase.

Several studies discussed an increase in stratospheric water vapor concentrations over the last decades (e.g. Nedoluha et al., 1998; Oltmans et al., 2000; Rosenlof, 2002). An increase in stratospheric water vapor would affect stratospheric ozone in several ways: The stratosphere is expected to cool as water vapor increases (Forster and Shine, 1999, 2002) which results in an more pronounced PSC formation (KirkDavidoff et al., 1999). Furthermore, increasing OH concentrations cause an enhanced homogeneous ozone loss (e.g. Dvortsov and Solomon, 2001). However, a recent analysis of different water vapor observations shows great discrepancies in lower stratospheric water vapor trends between the different data sets (Randel et al., 2004), so that the discussion on stratospheric water vapor trends is re-opened. Furthermore, the observations show remarkably low water vapor concentrations in the LS since 2001. Nevertheless, this and previous model studies indicate a not negligible impact of water vapor on stratospheric ozone that must be kept in mind discussing the future development of stratospheric ozone concentrations.

\section{Appendix: Chemical reactions}

Oxidation of $\mathrm{H}_{2} \mathrm{O}$ and $\mathrm{CH}_{4}$ :

$\mathrm{O}\left({ }^{1} \mathrm{D}\right)+\mathrm{H}_{2} \mathrm{O} \rightarrow 2 \mathrm{OH}$

$\mathrm{O}\left({ }^{1} \mathrm{D}\right)+\mathrm{CH}_{4} \rightarrow \mathrm{OH}+\mathrm{CH}_{3}$

Catalytic ozone destruction cycle:

$$
\begin{aligned}
& \mathrm{X}+\mathrm{O}_{3} \rightarrow \mathrm{XO}+\mathrm{O}_{2} \\
& \mathrm{XO}+\mathrm{O} \rightarrow \mathrm{X}+\mathrm{O}_{2} \\
& \hline \mathrm{O}_{3}+\mathrm{O} \rightarrow \mathrm{O}_{2}+\mathrm{O}_{2},
\end{aligned}
$$

where $\mathrm{X}$ can be one of the free radicals $\mathrm{H}, \mathrm{OH}, \mathrm{NO}, \mathrm{Cl}$ or $\mathrm{Br}$.

Additional $\mathrm{HO}_{\mathrm{x}}$-cycle:

$$
\begin{aligned}
\mathrm{OH}+\mathrm{O}_{3} & \rightarrow \mathrm{HO}_{2}+\mathrm{O}_{2} \\
\mathrm{HO}_{2}+\mathrm{O}_{3} & \rightarrow \mathrm{OH}+\mathrm{O}_{2}+\mathrm{O}_{2} \\
\mathrm{O}_{3}+\mathrm{O}_{3} & \rightarrow \mathrm{O}_{2}+\mathrm{O}_{2}+\mathrm{O}_{2}
\end{aligned}
$$

Coupling of $\mathrm{HO}_{\mathrm{x}}$ and $\mathrm{NO}_{\mathrm{x}}$ cycle:

$\mathrm{OH}+\mathrm{NO}_{2}+\mathrm{M} \rightarrow \mathrm{HNO}_{3}+\mathrm{M}$

Coupling of $\mathrm{HO}_{\mathrm{x}}$ and $\mathrm{ClO}_{\mathrm{x}}$ cycle:

$$
\begin{aligned}
\mathrm{OH}+\mathrm{HCl} & \rightarrow \mathrm{H}_{2} \mathrm{O}+\mathrm{Cl} \\
\mathrm{HO}_{2}+\mathrm{ClO} & \rightarrow \mathrm{HOCl}+\mathrm{O}_{2}
\end{aligned}
$$

Ozone production in methane oxidation chain:

$$
\begin{aligned}
\mathrm{CH}_{3} \mathrm{O}_{2}+\mathrm{NO} & \rightarrow \mathrm{CH}_{3} \mathrm{O}+\mathrm{NO}_{2} \\
\text { or } & \\
\mathrm{HO}_{2}+\mathrm{NO} & \rightarrow \mathrm{OH}+\mathrm{NO}_{2} \\
\mathrm{NO}_{2} & \stackrel{h v}{\rightarrow} \mathrm{NO}+\mathrm{O} \\
\mathrm{O}_{2}+\mathrm{O} & \rightarrow \mathrm{O}_{3}
\end{aligned}
$$

Heterogeneous reactions on PSCs and sulfate aerosols in CHEM:

$$
\begin{aligned}
\mathrm{HCl}+\mathrm{ClONO}_{2} & \rightarrow \mathrm{Cl}_{2}+\mathrm{HNO}_{3} \\
\mathrm{H}_{2} \mathrm{O}+\mathrm{ClONO} & \rightarrow \mathrm{HOCl}+\mathrm{HNO}_{3} \\
\mathrm{HOCl}+\mathrm{HCl} & \rightarrow \mathrm{Cl}_{2}+\mathrm{H}_{2} \mathrm{O} \\
\mathrm{N}_{2} \mathrm{O}_{5}+\mathrm{H}_{2} \mathrm{O} & \rightarrow 2 \mathrm{HNO}_{3}
\end{aligned}
$$


Acknowledgements. This study was partially funded by the EU project SCENIC. The model simulations were performed on the NEC SX-6 high performance computer of the German Climate Computing Centre (DKRZ), Hamburg. We thank M. Ponater for his helpful answers concerning the "last secrets" of the model ECHAM4.L39(DLR)/CHEM and H. Vömel for providing the Boulder water vapor dataset. J. Austin, P. Haynes and an anonymous referee are kindly acknowledged for their constructive reviews and helpful suggestions.

Edited by: P. H. Haynes

\section{References}

Austin, J., Butchart, N., and Swinbank, R. S.: Sensitivity of ozone and temperature to vertical resolution in a GCM with coupled stratospheric chemistry, Q. J. R. Meteorol. Soc., 123, 1405-1431, 1997.

Austin, J., Shindell, D., Beagley, S. R., Brühl, C., Dameris, M., Manzini, E., Nagashima, T., Newman, P., Pawson, S., Pitari, G., Rozanov, E., Schnadt, C., and Shepherd, T. G.: Uncertainties and assessments of chemistry-climate models of the stratosphere, Atmos. Chem. Phys., 3, 1-27, 2003,

SRef-ID: 1680-7324/acp/2003-3-1.

Bates, D. R. and Nicolet, M.: The photochemistry of atmospheric water vapor, J. Geophys. Res., 55, 301-327, 1950.

Benkovitz, C. M., Scholtz, M. T., Pacyna, J., Tarrason, L., Dignon, J., Voldner, E. C., Spiro, P. A., Logan, J. A., and Graedel, T. E.: Global gridded inventories of anthropogenic emissions of sulfur and nitrogen, J. Geophys. Res., 101, 29 239-29 253, 1996.

Brühl, C. and Crutzen, P. J.: MPIC two-dimensional model, in The atmospheric effects of stratospheric aircraft: Report of the 1992 models and measurement workshop, edited by: Prather, M. and Remsberg, E., NASA Reference Publ. 1292, pp. 703-706, Washington, DC, 1993.

Considine, D. B., Rosenfield, J. E., and Fleming, E. L.: An interactive model study of the influence of the Mount Pinatubo aerosol on stratospheric methane and water trends, J. Geophys. Res., 106, 27 711-27 727, 2001.

Dameris, M., Grewe, V., Ponater, M., Deckert, R., Eyring, V., Mager, F., Matthes, S., Schnadt, C., Stenke, A., Steil, B., Brühl, C., and Giorgetta, M. A.: Long-term changes and variability in a transient simulation with a chemistry-climate model employing realistic forcing, Atmos. Chem. Phys. Discuss., 5, 2297-2353, 2005 ,

SRef-ID: 1680-7375/acpd/2005-5-2297.

DeFoor, T. E., Robinson, E., and Ryan, S.: Early lidar observations of the June '91 Pinatubo eruption plume at Mauna Loa Observatory, Hawaii, Geophys. Res. Lett., 19, 187-190, 1992.

Dvortsov, V. L. and Solomon, S.: Response of the stratospheric temperatures and ozone to past and future increases in stratospheric humidity, J. Geophys. Res., 106, 7505-7514, 2001.

Evans, S. J., Toumi, R., Harries, J. E., Chipperfield, M. P., and Russell III, J. M.: Trends in the stratospheric humidity and the sensitivity of ozone to these trends, J. Geophys. Res., 103, 8715-8725, 1998.

Fioletov, V. E., Bodeker, G. E., Miller, A. J., McPeters, R. D., and Stolarski, R.: Global and zonal total ozone variations estimated from ground-based and satellite measurements: 1964-2000, J. Geophys. Res., 107, 4647, doi:10.1029/2001JD001350, 2002.

Forster, P. M. de F. and Shine, K. P.: Stratospheric water vapour changes as a possible contributor to observed stratospheric cooling, Geophys. Res. Lett., 26, 3309-3312, 1999.

Forster, P. M. de F. and Shine, K. P.: Assessing the climate impact of trends in stratospheric water vapor, Geophys. Res. Lett., 29, 1086, doi:10.1029/2001GL013909, 2002.

Grewe, V., Brunner, D., Dameris, M., Grenfell, J. L., Hein, R., Shindell, D., and Staehelin, J.: Origin and variability of upper tropospheric nitrogen oxides and ozone at northern mid-latitudes, Atmos. Environ., 35, 3421-3433, 2001.

Grewe, V., Dameris, M., Fichter, C., and Sausen, R.: Impact of aircraft $\mathrm{NO}_{\mathrm{x}}$ emissions. Part 1: Interactively coupled climatechemistry simulations and sensitivities to climate-chemistry feedback, lightning and model resolution, Meteorol. Z., 3, 177186, 2002.

Grewe, V., Shindell, D. T., and Eyring, V.: The impact of horizontal transport on the chemical composition in the tropopause region: Lightning $\mathrm{NO}_{x}$ and streamers, Adv. Space Res., 33, 1058-1061, 2004.

Hanisco, T. F., Lanzendorf, E. J., Wennberg, P. O., Perkins, K. K., Stimpfle, R. M., Voss, P. B., Anderson, J. G., Cohen, R. C., Fahey, D. W., Gao, R. S., Hintsa, E. J., Salawitch, R. J., Margitan, J. J., McElroy, C. T., and Midwinter, C.: Sources, sinks and the distribution of $\mathrm{OH}$ in the lower stratosphere, J. Phys. Chem. A, 105, 1543-1553, 2001.

Hanson, D. and Mauersberger, K.: Laboratory studies of nitric acid trihydrate: Implications for the south polar stratosphere, Geophys. Res. Lett., 15, 855-858, 1988.

Hao, W. M., Liu, M.-H., and Crutzen, P. J.: Estimates of annual and regional releases of $\mathrm{CO}_{2}$ and other trace gases to the atmosphere from fires in the tropics, based on the FAO statistics for the period 1975-1980, Vol. 84 of Fire in the Tropical Biota, Ecological Studies, pp. 440-462, Springer-Verlag, New York, 1990.

Hein, R., Dameris, M., Schnadt, C., Land, C., Grewe, V., Köhler, I., Ponater, M., Sausen, R., Steil, B., Landgraf, J., and Brühl, C.: Results of an interactively coupled atmospheric chemistrygeneral circulation model: comparison with oberservations, Ann. Geophys., 19, 435-457, 2001,

SRef-ID: 1432-0576/ag/2001-19-435.

IPCC (Intergovernmental Panel on Climate Change): Aviation and the global atmosphere, 373 pp., Cambridge University Press, Cambridge, UK, 1999.

IPCC (Intergovernmental Panel on Climate Change): Climate Change 2001 - The scientific basis, 881 pp., Cambridge University Press, New York, USA, 2001.

Kinne, S., Toon, O. B., and Prather, M. J.: Buffering of stratospheric circulation by changing amounts of tropical ozone - a Pinatubo case study, Geophys. Res. Lett., 19, 1927-1930, 1992.

Kirk-Davidoff, D. B., Hintsa, E. J., Anderson, J. G., and Keith, D. W.: The effect of climate change on ozone depletion through changes in stratospheric water vapour, Nature, 402, 399-401, 1999.

Land, C., Ponater, M., Sausen, R., and Roeckner, E.: The ECHAM4.L39(DLR) atmosphere GCM - Technical description and model climatology, DLR Forschungsbericht 1999-31, ISSN 1434-8454, Köln, 1999.

Lawrence, M. G., Jöckel, P., and von Kuhlmann, R.: What does the 
global mean $\mathrm{OH}$ concentration tell us?, Atmos. Chem. Phys., 1, 37-49, 2001,

SRef-ID: 1680-7324/acp/2001-1-37.

Michelsen, H. A., Irion, F. W., Manney, G. L., Toon, G. C., and Gunson, M. R.: Features and trends in Atmospheric Trace Molecule Spectroscopy (ATMOS) version 3 stratospheric water vapor and methane measurements, J. Geophys. Res., 105, 22 713-22 724, 2000.

Nedoluha, G. E., Bevilacqua, R. M., Gomez, R. M., Siskind, D. E., Hicks, B. C., Russell III, J. M., and Connor, B. J.: Increases in middle atmospheric water vapor as observed by the Halogen Occultation Experiment and the ground-based Water Vapor Millimeter-wave Spectrometer from 1991 to 1997, J. Geophys. Res., 103, 3531-3543, 1998.

Oltmans, S. J., Vömel, H., Hofmann, D. J., Rosenlof, K. H., and Kley, D.: The increase in stratospheric water vapor from balloonborne frostpoint hygrometer measurements at Washington D.C., and Boulder, Colorado, Geophys. Res. Lett., 27, 34533456, 2000.

Pawson, S., Kodera, K., Hamilton, K., Shepherd, T. G., Beagley, S. R., Boville, B. A., Farrara, J. D., Fairlie, T. D. A., Kitoh, A., Lahoz, W. A., Langematz, U., Manzini, E., Rind, D. H., Scaife, A. A., Shibata, K., Simon, P., Swinbank, R., Takacs, L., Wilson, R. J., Al-Saadi, J. A., Amodei, M., Chiba, M., Coy, L., de Grandpre, J., Eckman, R. S., Fiorino, M., Grose, W. L., Koide, H., Koshyk, J. N., Li, D., Lerner, J., Mahlman, J. D., McFarlane, N. A., Mechoso, C. R., Molod, A., O’Neill, A., Pierce, R. B., Randel, W. J., Rood, R. B., and Wu, F.: The GCM-reality intercomparison project of SPARC (GRIPS): scientific issues and initial results, Bull. Am. Meteorol. Soc., 81, 781-796, 2000.

Randel, W. J., Wu, F., Oltmans, S. J., Rosenlof, K., and Nedoluha, G. E.: Interannual changes of stratospheric water vapor and correlations with tropical tropopause temperatures, J. Atmos. Sci., 61, 2133-2148, 2004.

Roeckner, E., Arpe, K., Bengtsson, L., Christoph, M., Claussen, M., Dümenil, L., Esch, M., Giorgetta, M., Schlese, U., and Schulzweida, U.: The atmospheric general circulation model ECHAM-4: Model description and simulation of present-day climate, Report No. 218, Max-Planck-Institut für Meteorologie, Hamburg, 1996.

Rosenlof, K. H.: Transport changes inferred from HALOE water and methane measurements, J. Met. Soc. Jap., 80, 831-848, 2002.
Rosenlof, K. H., Oltmans, S. J., Kley, D., Russell III, J. M., Chiou, E.-W., Chu, W. P., Johnson, D. G., Kelly, K. K., Michelsen, H. A., Nedoluha, G. E., Remsberg, E. E., Toon, G. C., and McCormick, M. P.: Stratospheric water vapor increases over the past half-century, Geophys. Res. Lett., 28, 1195-1198, 2001.

Salby, M. L.: Fundamentals of Atmospheric Physics, 627 pp., Academic Press, San Diego, Calif., 1996.

Schnadt, C., Dameris, M., Ponater, M., Hein, R., Grewe, V., and Steil, B.: Interaction of atmospheric chemistry and climate and its impact on stratospheric ozone, Clim. Dyn., 17, 501-517, 2002.

Schmitt, A. and Brunner, D.: Emissions from aviation and their development over time, in: Pollutants from air traffic - results of atmospheric research 1992-1997, edited by: Schumann, U., Chloud, A., Ebel, A., Kärcher, B., Pak, H., Schlager, H., Schmitt, A., and Wendling, P., Vol. 97-04 of DLR-Mitt., 37-52, DLR Köln, Germany, 1997.

Seinfeld, J. H. and Pandis, S. N.: Atmospheric chemistry and physics: From air pollution to climate change, 1360 pp., John Wiley \& Sons, Inc., New York, NY, 1998.

SPARC: Assessment of trends in the vertical distribution of ozone, SPARC Report \#1, WMO Ozone Research and Monitoring Project Report \#43, 1998.

SPARC: Assessment of upper tropospheric and stratospheric water vapour, WCRP \#113, WMO/TD \#1043, SPARC Report \#2, 2000.

Spivakovsky, C. M., Logan, J. A., Montzka, S. A., Balkanski, Y. J., Foreman-Fowler, M., Jones, D. B. A., Horowitz, L. W., Fusco, A. C., Brenninkmeijer, C. A. M., Prather, M. J., Wofsy, S. C., and McElroy, M. B.: Three-dimensional climatological distribution of tropospheric OH: Update and evaluation, J. Geophys. Res., 105, 8931-8980, 2000.

Steil, B., Dameris, M., Brühl, C., Crutzen, P. J., Grewe, V., Ponater, M., and Sausen, R.: Development of a chemistry module for GCMs: first results of a multiannual integration, Ann. Geophys., 16, 205-228, 1998,

SRef-ID: 1432-0576/ag/1998-16-205.

WMO (World Meteorological Organization): Scientific assessment of ozone depletion: 2002, Report No. 47, 498 pp., Geneva, 2003.

Yienger, J. J. and Levy, H.: Empirical model of global soil-biogenic $\mathrm{NO}_{x}$ emissions, J. Geophys. Res., 100, 11 447-11 464, 1995.

Zhou, X., Geller, M. A., and Zhang, M.: Cooling trend of the tropical cold point tropopause temperatures and its implications, J. Geophys. Res., 106, 1511-1522, 2001. 